\title{
EXERCISE IMPROVES BLADDER FUNCTION IN DIABETIC MICE
}

\author{
by
}

\section{MANASI HEMANT VADHAVKAR}

B. PHARM, University of Mumbai, 2006

\section{A THESIS SUBMITTED IN PARTIAL FULFILLMENT OF THE REQUIREMENTS FOR THE DEGREE OF MASTER OF SCIENCE}

in

THE FACULTY OF GRADUATE STUDIES

(Experimental Medicine)

\section{THE UNIVERSITY OF BRITISH COLUMBIA}

(Vancouver)

October 2009

(C) Manasi Vadhavkar, 2009 


\section{ABSTRACT}

Type 2 diabetes accounts for more than $90 \%$ of diabetes mellitus. Urinary bladder dysfunction is a frequent complication of diabetes and can lead to urinary incontinence (UI), infection and impaired bladder emptying leading to retention of urine and loss of sensation in the patients. Of these, UI is a most debilitating condition that leads to decreased quality of life especially in women. It is estimated to affect approximately $30-50 \%$ of the elderly. Exercise is the initial recommended management strategy in diabetes but its effect on diabetic urinary bladder dysfunction or urinary incontinence (UI) is unknown. We hypothesize that exercise improves bladder dysfunction and reduces the voiding frequency in the $d b / d b$ mouse, a frequently used animal model of type 2 diabetes.

Thirty- two $d b / d b$ female mice (BKS. Cg-m+/+Lepr $d b / \mathrm{J}$ strain) and their age matched wild type controls (WT) were used. Mice were equally divided into sedentary and exercise groups. Mice were exercised for one hour everyday for 8 weeks (speed of 5.2 meters/min). This moderate level of exercise did not alter the body weight or blood glucose levels of $d b / d b$ mice. We performed a voiding pattern test, cystometric analysis and reactivity of isolated bladder strips in WT and $d b / d b$ mice, both sedentary and exercised.

Diabetes increased the frequency of voiding, bladder capacity and residual volume. Exercise decreased voiding frequency in $d b / d b$ mice. In cystometric analysis, the bladder capacity, micturition pressure, micturition volume and residual volume were decreased significantly compared to $d b / d b$ sedentary mice. Isolated strips of bladder muscle from sedentary $d b / d b$ mice were more responsive to carbachol than strips from $d b / d b$ exercise mice.

In summary, exercise improved bladder function in diabetic mice by reducing voiding frequency and improving urodynamic parameters; exercise did not alter the contractility of the detrusor muscle in $d b / d b$ mice. 


\section{TABLE OF CONTENTS}

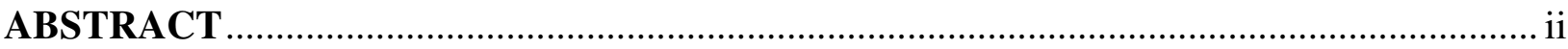

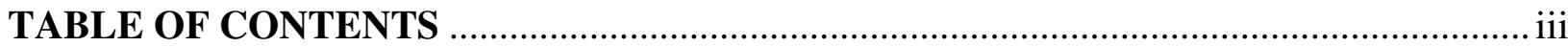

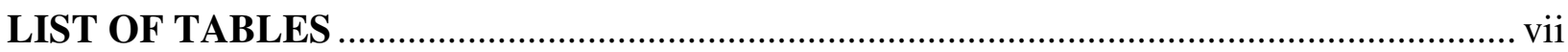

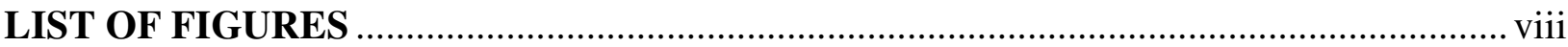

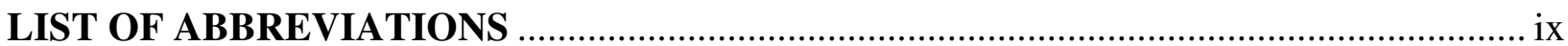

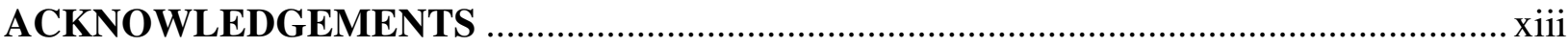

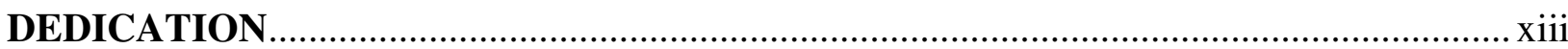

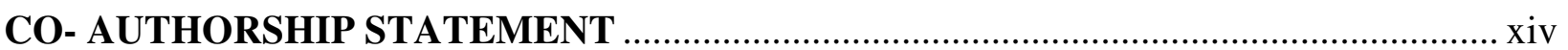

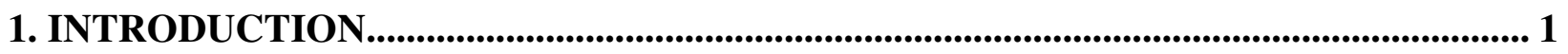

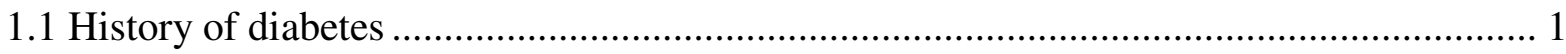

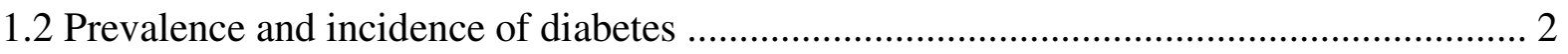

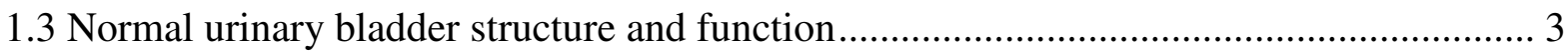

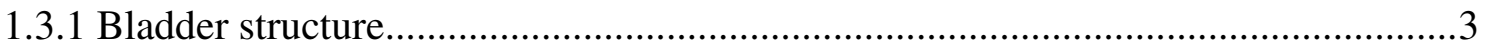

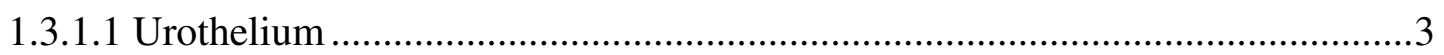

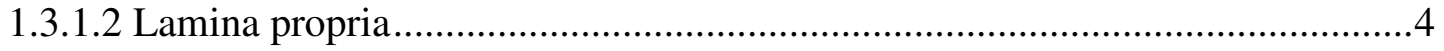

1.3.1.3 Detrusor smooth muscle ………………………......................................

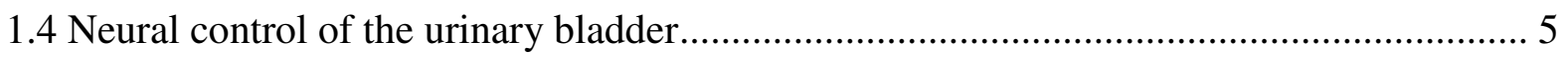

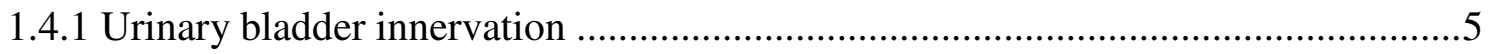

1.4.2 Parasympathetic system................................................................................

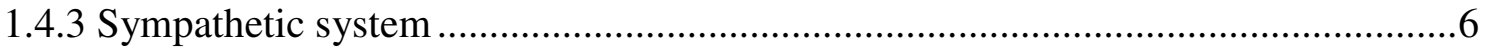

1.4.4 Non- adrenergic, non- cholinergic (NANC) system............................................

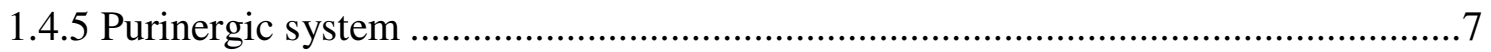




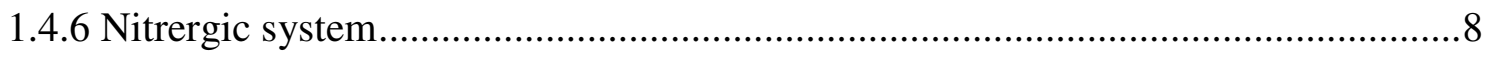

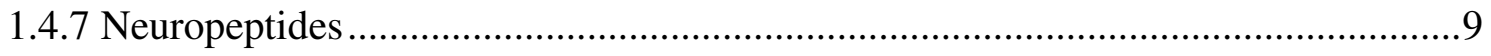

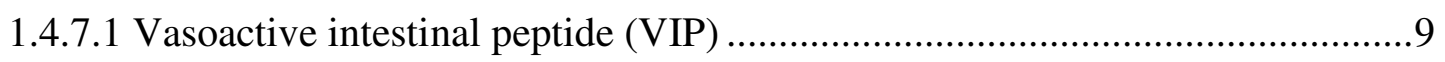

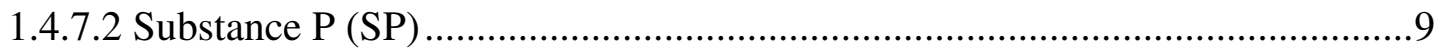

1.4.7.3 Calcitonin gene related peptide (CGRP) …………….................................10

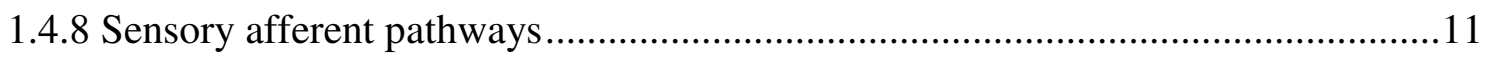

1.5 Urinary bladder dysfunction and urinary incontinence in diabetes ............................... 11

1.5.1 Clinical studies: prevalence, incidence and pathophysiology ................................11

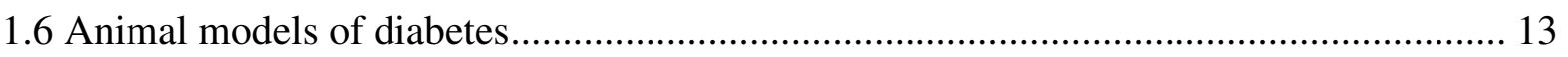

1.6.1 Animal studies of urinary bladder dysfunction ................................................14

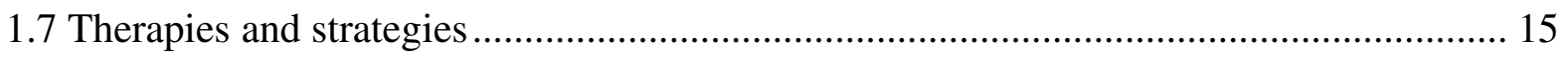

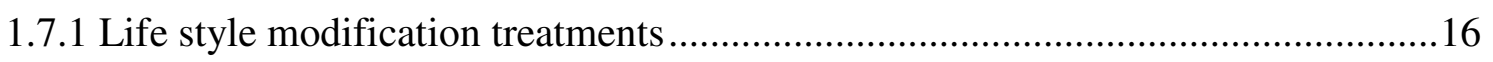

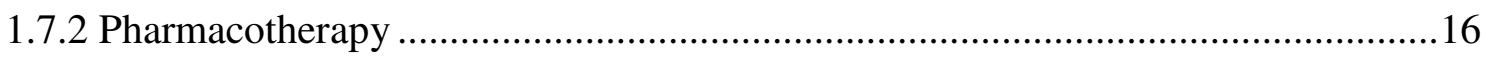

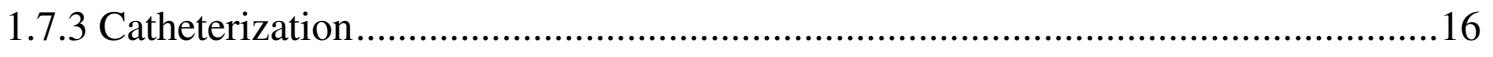

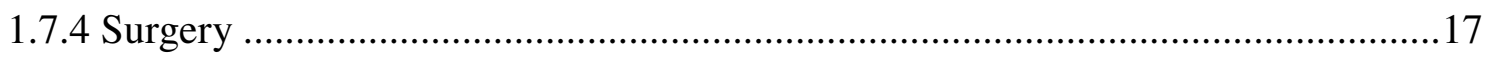

1.8 Mechanisms of diabetic bladder dysfunction and urinary incontinence.......................... 17

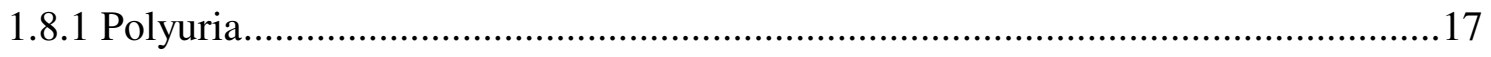

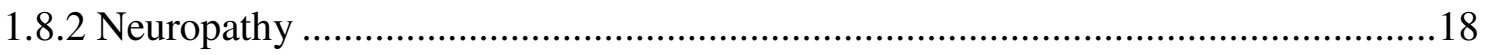

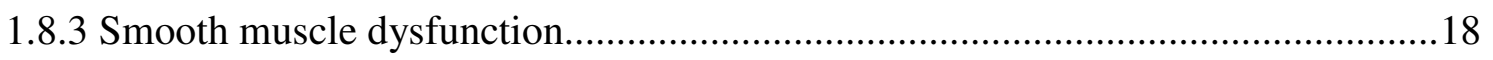

1.8.4 Cholinergic and adrenergic receptor alterations .................................................18

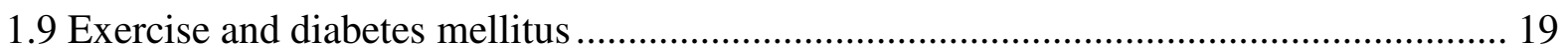

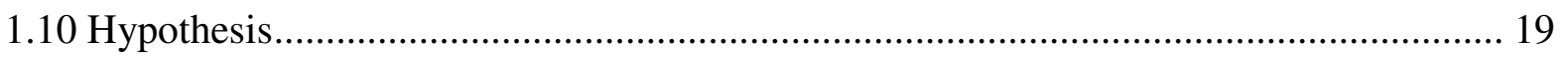

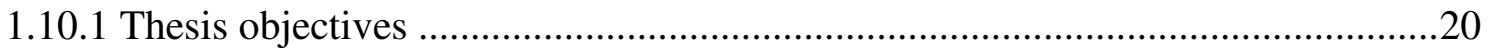

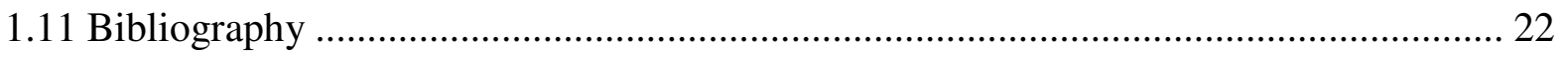


2. EXERCISE IMPROVES BLADDER DYSFUNCTION IN DIABETIC MICE............... 35

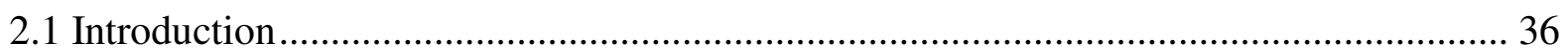

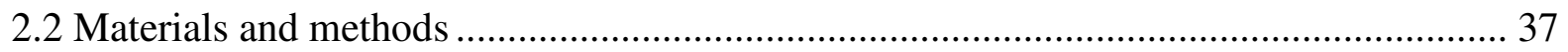

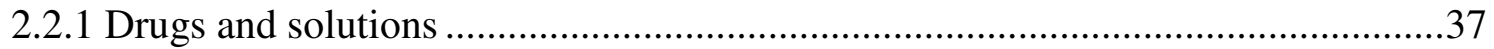

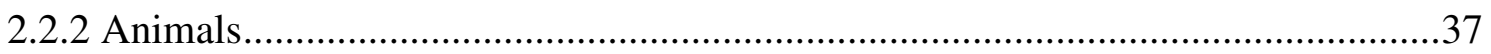

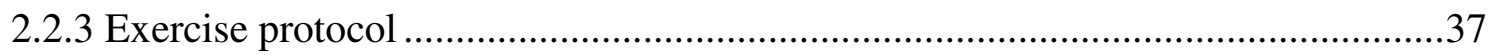

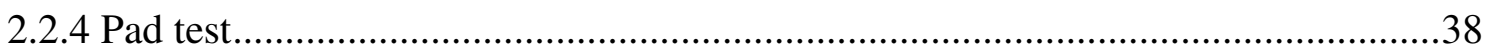

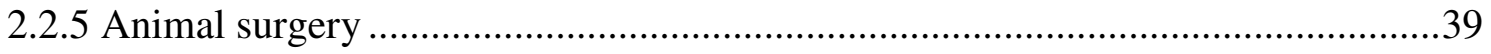

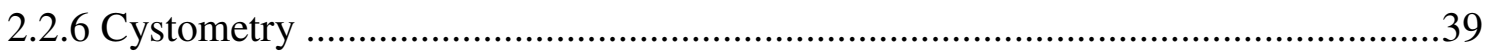

2.2.7 Pharmacological response measurements ...........................................................40

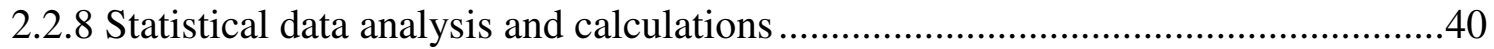

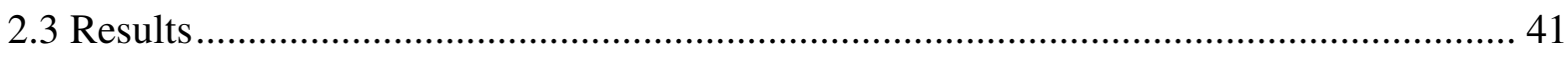

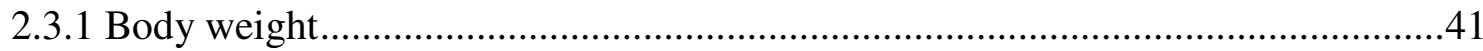

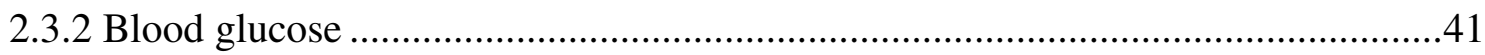

2.3.3 Voiding pattern and frequency ……………......................................................42

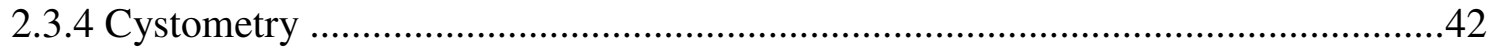

2.3.5 Pharmacology of bladder strips ...........................................................................43

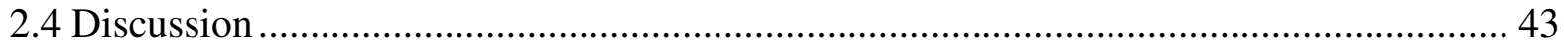

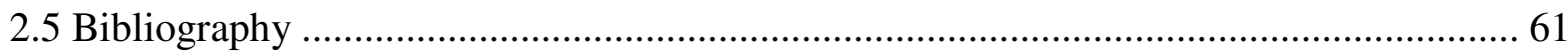

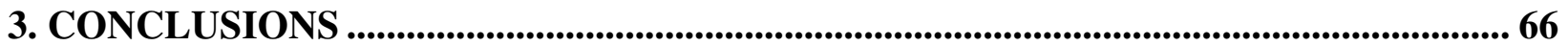

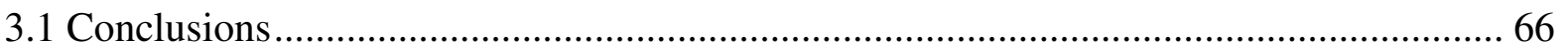

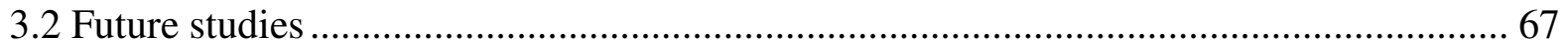

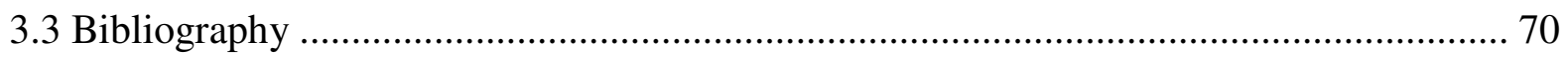




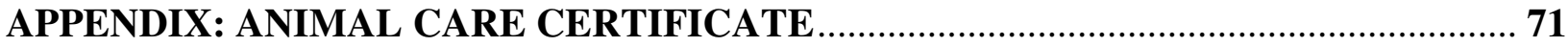




\section{LIST OF TABLES}

Table 1-1 General urodynamic parameters in diabetes and animal models of diabetes ............. 21

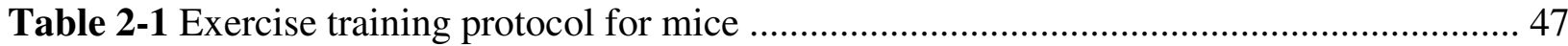

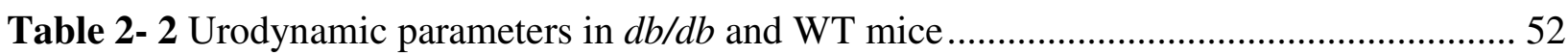

Table 2- $3 \mathrm{E}_{\max }$ and $\mathrm{EC}_{50}$ values for $\mathrm{CCh}$ concentration response curves .............................. 59 


\section{LIST OF FIGURES}

Figure 2-1 Age and exercise- related changes in body weights of mice................................. 48

Figure 2-2 Age and exercise- related changes in blood glucose values of mice ..................... .49

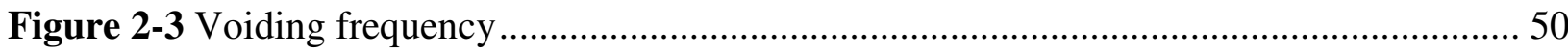

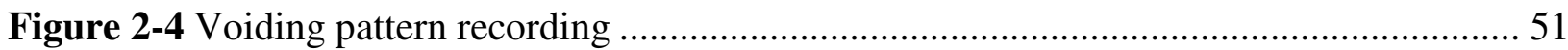

Figure 2-5 Cystometrogram tracings in mice .......................................................... 54

Figure 2-6 Urodynamic measurements in mice ........................................................... 58

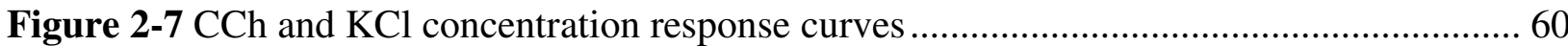




\section{LIST OF ABBREVIATIONS}

ADA: American Diabetes Association

$\alpha$ : Alpha

ATP: Adenosine triphosphate

BP: Basal pressure

$\beta$ : Beta

Bcap: Bladder capacity

Bcom: Bladder compliance

BMI: Body mass index

CCh: Carbachol

CGRP: Calcitonin gene related peptide

CRC: Concentration response curve

COX: Cycloxygenases

$d b / d b:$ Diabetic

DM: Diabetes mellitus

DAG: Diacylglycerol

EPINCONT: Epidemiology of incontinence in the county of Nord-Trøndelag

IDDM: Insulin dependent diabetes mellitus

IP3: Inositol 1, 4, 5 - tri phosphate

IMP: Inter micturition pressure

$\mathrm{KCl}$ : Potassium chloride

LUTS: Lower urinary tract symptoms

MF: Micturition frequency

MP: Micturition pressure 
MV: Micturition volume

Ml: Millilitres

mM: millimolar

mmol/L: millimole/litre

NDDG: National Diabetes Data Group

NIH: National Institute of Health

NIRS: Near infrared spectroscopy

NANC: Non adrenergic non cholinergic

NIDDM: Non-insulin dependent diabetes mellitus

NO: Nitric oxide

NOS: Nitric oxide synthase

OAB: Overactive bladder

$o b / o b:$ Obese

PI: Phosphatidylinositol

PSS: Physiological salt solution

PMC: Pontine micturition centre

PVR: Post void residual

RT-PCR: Reverse transcriptase- polymerase chain reaction

SA: Spontaneous activity

STZ: Streptozotocin

SP: Substance P

TP: Threshold pressure

TXA2: Thromboxane A2

tHbO2: Tissue oxyhaemoglobin

tHb: Deoxyhaemoglobin 
tBV: Total blood volume

UI: Urinary incontinence

VIP: Vasoactive intestinal polypeptide

WT: Wild- type

WHO: World Health Organization 


\section{ACKNOWLEDGEMENTS}

I would like to express my deepest gratitude to my supervisors, Dr. Ismail Laher and Dr. Lynn

Stothers, for their constant support and guidance for my Master's thesis. Dr. Ismail Laher was always inspiring and encouraged me throughout my study with his wide knowledge and vast experience and Dr. Lynn Stothers gave me a proper direction to my experimental studies.

I would also like to thank Dr. Vincent Duronio (Head of Experimental Medicine Program) and Mr. Patrick Carew (Graduate Secretary) for their friendly support throughout my studies at UBC.

I am really grateful to Dr. Tamer Aboushwareb (Wake Forest Institute for Regenerative Medicine) for his technical guidance on performing surgery and cystometry.

Thanks also to my lab members Dr. Saeid Golbidi and Ms. Nada Sallam for providing an enjoyable atmosphere and cooperation during my research work and to Mr. Andy Jeffries for his help in the procurement of research materials.

Finally, I would like to express my special thanks to my parents for their unconditional love, constant support, patience and encouragement all through my years of education. 


\title{
To my parents
}

\author{
for their
}

love and support 


\section{CO- AUTHORSHIP STATEMENT}

The overall concept for the proposal to examine the effects of exercise on bladder function in diabetic mice was suggested by Dr. Ismail Laher and Dr. Lynn Stothers. Details of the specific nature of the experiments and the scope of the thesis work were engineered in discussions between Dr. Stothers and myself. I received training from Dr. Jason Sea (UBC Dept. Urology) in the surgical skills required to routinely and successfully perform mouse cystometry. All the experiments in this thesis (Chapter 2) were carried out by myself; I performed all the surgeries, exercised the mice, monitored blood glucose and animal weights, collected cystometric parameters, recorded and analyzed the data, wrote the thesis and manuscript. 


\section{INTRODUCTION}

\subsection{History of diabetes}

'Diabetes' is a Greek word which means excessive urine production while 'Mellitus' originates from the Latin word 'mel' which means honey and implies that during diabetes mellitus, there is excessive urine production that is accompanied by high concentrations of glucose. The first note of diabetes was made by the Egyptian physician Hyse-Ra 1552 BCE (Canadian Diabetes Association, 2007). Many discoveries were made in the $18^{\text {th }}$ century; in 1869, Paul Langerhans, a German medical student reported in his dissertation that the pancreas contained two sets of cells, one secreting pancreatic juice and other with an unknown function. These latter cells were later identified as 'Islets of Langerhans'. The specific role of the pancreas was further refined in 1916 when Edward Sharpey Schafer suggested that islet cells secreted a glucose regulating hormone which he termed as 'insulin.' In 1921, Banting and Best working in the lab of Dr. Macleod reported in a paper to the American Physiological Society that pancreatic extracts have beneficial effects on diabetes and in 1923; insulin was isolated and tested in a human being. For this amazing discovery, both Dr. Banting and Dr. Macleod shared a nobel prize (Eknoyan and Nagy, 2005).

In 1979, a workgroup sponsored by the National Diabetes Data Group (NDDG) of the National Institute of Health (NIH) and endorsed by the World Health Organization (WHO) classified diabetes mellitus into two main types; insulin dependent DM (IDDM) and non-insulin dependent DM (NIDDM). In 1997, the American Diabetes Association (ADA) proposed changes to the NDDG/ WHO classification by eliminating some terms. The new clinical classification of DM is: a) Type 1 diabetes mellitus b) Type 2 diabetes mellitus. 
a) Type 1 diabetes mellitus- This type of DM comprises of approximately 5- $10 \%$ of all cases. It results from $\beta$ - cell destruction leading to a total loss of insulin secretion and insulin deficiency. Risk factors for type $1 \mathrm{DM}$ include genetic, autoimmune and environmental factors.

b) Type 2 diabetes mellitus- This type of DM comprises of $90-95 \%$ of all cases. It is characterized by insulin resistance in muscle, liver and adipose tissue. The risk of developing type 2 DM increases with age, obesity and lack of physical activity. Clinically, type 2 diabetes mellitus is characterized by polyuria (excessive urination), polydipsia (excessive thirst), excessive hunger and fatigue (Harris, 2004; Deshpande, 2008).

\subsection{Prevalence and incidence of diabetes}

Diabetes mellitus is a leading cause of death in US and Canada and the number of people suffering from type $2 \mathrm{DM}$ is increasing at an alarming rate. It is estimated that over two million people in Canada, thirteen million people in US and 246 million people globally suffer from type 2 DM. This figure is expected to rise, so that in 2050, it is estimated that around $12-29$ million people in Canada and US and around 380 million people in the world will suffer from diabetes mellitus (Kung, 2008; Boyle, 2001; American Diabetes Association). The Canadian Centre for Disease Control and Prevention has reported that the prevalence of diabetes increases with age and that approximately 41, 500 Canadians die each year from diabetes. The Canadian Diabetes Association reports that diabetes costs $\$ 15.6$ million to the Canadian health care system (Canadian Diabetes Association, 2007a).

Diabetes leads to serious microvascular (neuropathy, nephropathy, and retinopathy) and macrovascular (cardiovascular, peripheral vascular disease, stroke) complications, with the risk for developing microvascular complications being greater than that for macrovascular complications (Stratton, 2000). Diabetes also causes urological dysfunction which leads to 
debilitating symptoms such as impaired bladder sensation, urinary retention, bladder paralysis and incomplete voiding. Although these symptoms are well recognized, the pathophysiology of dysfunction has not been completely elucidated and current treatments are ineffective in preventing the damage.

\subsection{Normal urinary bladder structure and function}

The urinary bladder is a hollow, muscular, distensible organ which serves as a reservoir for storage and periodic release of urine (Steers, 1992). Urine enters the bladder through ureters and exits via the urethra. Bladder capacity ranges from 400-500 $\mathrm{ml}$ in humans, and in rodents, it differs between mice $(0.15 \mathrm{ml})$ and rats $(1.5 \mathrm{ml})$ (Andersson and Arner, 2004). In humans, average bladder emptying rate is about 5- 6 times a day and changes in this frequency indicate bladder dysfunction. The urinary bladder is divided into two distinct regions: a) the bladder dome or bladder body which mainly consists of detrusor smooth muscle and b) bladder neck or bladder base; a small region which consists of the trigone and extends from the ureters to the urethra (Andersson and Arner, 2004).

\subsubsection{Bladder structure}

The urinary bladder is composed of different cell layers: serosa, muscularis, sub mucosa, muscularis muscosa and lamina propria (Lewis, 2000). But the three important layers are urothelium, lamina propria and smooth muscle.

1.3.1.1 Urothelium: The urothelium is a thin layer of transitional epithelium and has a turnover time of 6 weeks in mice. A cross sectional view of the urothelium shows that it is composed of three cell layers with a distinct cell type in each layer i) a basal cell layer with small germinal 
cells ii) an intermediate cell layer with moderately sized cells and iii) a superficial cell layer with hexagonal shaped umbrella cells (Lewis, 2000; Birder, 2005). The umbrella cells are joined by tight gap junctions and act as a barrier for the movement of substances between urine and blood. Initially, the urothelium was considered to have only a barrier function but later research has shown that it also has a sensory transduction function. It is now accepted that the urothelium is a responsive structure which can sense physiological and chemical stimuli as well as being able to release different signalling molecules. Some additional properties of the urothelium include expression and release of neurotransmitters, activation of stretch activated channels and innervation by afferent nerves (Lewis, 2000; de Groat, 2004; Birder, 2005).

1.3.1.2 Lamina propria: This is a cell layer below the urothelium consisting of connective and elastic tissues, blood vessels and some myofibroblasts. Within the lamina propria lies the muscularis mucosa (Wiseman et al, 2002; Wiseman et al, 2003).

1.3.1.3 Detrusor smooth muscle: The detrusor smooth muscle is composed of three layers; outer and inner layers with longitudinal cells and a middle layer with circular cells, which forms bundles of muscle cells. The smooth muscle cells have a meshwork appearance and are highly distensible, allowing the bladder to store large amounts of urine. The bundles vary in size and have connective tissue that is rich in collagen and elastin. Smooth muscle cell interactions within the bundles are important to determine proper functioning of urinary bladder (Andersson and Arner, 2004; Longhurst and Uvelius, 2001). 


\subsection{Neural control of the urinary bladder}

\subsubsection{Urinary bladder innervation}

The physiology of bladder control mainly involves regulation by central nervous system. The bladder is innervated by both efferent (motor) nerves as well as the afferent (sensory) nerves, and proper coordination of their activity is required for micturition and storage functions of bladder. During storage, the bladder smooth muscle (detrusor) relaxes and the bladder outlet contracts (closed); this helps in the filling of the bladder at low intravesical pressure whereas during micturition there is a contraction of bladder smooth muscle (detrusor) and a relaxation of the bladder outlet muscle, resulting in proper evacuation or voiding (de Groat and Yoshimura, 2001). These contraction and relaxation mechanisms are controlled predominantly by three sets of nerves: sacral parasympathetic (pelvic), thoracolumbar sympathetic (hypogastric) and somatic (pudendal). Nonadrenergic noncholinergic (NANC) nerves also play an important role in bladder function. Bladder contraction occurs via stimulation of the parasympathetic nerve activity which causes voiding whereas bladder relaxation is due the thoracolumbar sympathetic nerve activity which helps in filling of the bladder (Longhurst and Uvelius, 2001; de Groat and Yoshimura, 2001; Sugaya et al, 2005).

\subsubsection{Parasympathetic system}

Sacral parasympathetic nerves (pelvic) are the major excitatory inputs to the urinary bladder and are primarily responsible for the voiding function of the bladder. Preganglionic parasympathetic axons originate in the S2- S4 region of the intermediolateral column of the spinal cord. The preganglionic axons terminate on the postganglionic neurons in the bladder wall and release acetylcholine which activates the postjunctional nictonic receptors (Yoshimura et al, 2008). 
The postganglionic parasympathetic nerve terminal release acetylcholine that activates muscarinic receptors which are found in all parts of the urinary bladder with the density being greater in the bladder body compared to the bladder base (Longhurst and Uvelius, 2001; Michel, 2005; Yoshimura et al, 2008). Two subtypes of muscarinic receptors found in the urinary bladder are M2 and M3 with the density of M2 receptors being 3 to 10 fold higher than the density of M3 receptors. The mechanism of bladder contraction via M3 receptors requires coupling to phospholipase $\mathrm{C}$ and stimulating the hydrolysis of the phosphatidylinositol (PI) to inositol 1, 4, 5- triphosphate (IP3) and diaceylglycerol (DAG). M2 receptor mediated contraction is by coupling to an inhibitory $\mathrm{G}$ protein, causing inhibition of adenylate cyclase and beta- adrenergic induced formation of cyclic AMP and thus preventing norepinephrine induced relaxation (Longhurst and Uvelius, 2001).

In animal studies, M3 receptor knockout mice have urinary bladders that are more distended due to urinary retention, and bladder strips show no response to muscarinic agents. In M2 receptor knockout mice, similar or no responses of bladder strips to carbachol compared to control mice were seen (Stengel et al, 2002; Choppin, 2002). Thus, M3 receptors are responsible for bladder contraction although there is a high density of M2 receptors in the bladder.

\subsubsection{Sympathetic system}

The sympathetic nervous system is involved in maintaining continence during bladder filling. Preganglionic neurons of the sympathetic efferent (hypogastric) nerves originate from segments T11- L2 of the spinal cord. The postganglionic sympathetic neurons release norepinephrine which causes relaxation of bladder body and contraction of the bladder base (Longhurst and Uvelius, 2001; Roberts, 2008).

The urinary bladder body has mainly beta $(\beta)$ receptors and a few alpha $(\alpha)$ receptors, whereas the bladder base and urethra have a higher density of $\alpha$ receptors and only a very few $\beta$ 
receptors. In the human urinary bladder, the expression of $\alpha$ receptors in the bladder base consists of $\alpha 1(80 \%)$ and $\alpha 2(20 \%)$ receptors. Studies using RT- PCR (reverse transcriptasepolymerase chain reaction) and RNase protection assays show that $60-70 \%$ of $\alpha 1$ adrenergic receptors $\alpha 1-\mathrm{d}$ subtype and the remaining being of the $\alpha 1$-a subtype. There is an equal expression of $\alpha 1-a, \alpha 1-b$ and $\alpha 1-d$ subtype receptors in rat detrusor muscle.

$\beta$ adrenoceptors are found in the detrusor muscle of humans as well as in animals. Initially it was believed that $\beta 2$ receptors were the predominant subtype responsible for relaxation, but two more subtypes ( $\beta 1$ and $\beta 3$ ) have been characterized in detrusor muscle. Although these receptors are expressed in smooth muscle, there is no agreement on the subtype responsible for functional responses to $\beta$ agonists (Longhurst and Uvelius, 2001; Andersson, 1999). Activation of $\beta$ adrenoceptors coupled through stimulatory $G$ proteins results in the activation of adenylate cyclase and increased levels of cyclic AMP causing urinary bladder relaxation

\subsubsection{Non- adrenergic, non- cholinergic (NANC) system}

Other than acetylcholine and norepinephrine, additional endogenous substances are also involved in the excitation and inhibition of urinary bladder. These substances include ATP, nitric oxide, neuropeptides such as vasoactive intestinal polypeptide, endothelins, tachykinins, angiotensin and cyclooxygenases such as prostanoids. Although the NANC component contributes to motor transmission in isolated human detrusor strips, its role in whole bladder function is still disputed (Andersson and Arner, 2004; Andersson, 1993).

\subsubsection{Purinergic system}

Acetylcholine is the primary neurotransmitter responsible for bladder voiding mechanisms but it is clear that a co- transmitter is released when cholinergic nerves to the 
bladder are stimulated. The major NANC transmitter released from the bladder body after pelvic nerve stimulation is ATP and the bladder has a heterogeneous population of ATP receptors. ATP acts on two types of purinergic receptors, $\mathrm{P} 2 \mathrm{X}$ and $\mathrm{P} 2 \mathrm{Y}$ receptors. Activation of $\mathrm{P} 2 \mathrm{Y}$ receptors leads to bladder relaxation while activation of $\mathrm{P} 2 \mathrm{X}$ receptors leads to contraction of bladder smooth muscle (Andersson and Arner, 2004).

The expression of purinergic receptors is high in some species (cat, mouse and rabbit), moderate in others (guinea pig, rat and dog) and reduced in pigs and humans. So far, seven subtypes of $\mathrm{P} 2 \mathrm{X}$ receptors and eight subtypes of $\mathrm{P} 2 \mathrm{Y}$ receptors have been indentified. The purinergic receptor subtype dominant in the rat and mouse bladder is P2X1. Knockout studies in mice for P2X3 receptors indicate impaired bladder function whereas P2X1 knock out mice has normal bladder function (Longhurst and Uvelius, 2001).

\subsubsection{Nitrergic system}

Along with ATP, nitric oxide (NO) is an important NANC transmitter found in the bladder neck of various species. Nitric oxide production plays a role in mediating signals required for regulatory mechanisms in the urogenital tract (Hedlund, 2005; Andersson, 1993). Nitric oxide is synthesized by NOS (NO-synthase), which catalyze the conversion of L- arginine to NO and L- citrulline. Three types of NOS have been identified: endothelial NOS (eNOS), inducible NOS (iNOS) and neuronal NOS (nNOS). nNOS plays a key role in modulating the smooth muscle tone in the bladder detrusor muscle and controlling sphincter tone for micturition. There is conflicting evidence about the role of NO in the detrusor muscle of bladder.

In animal studies, NO causes detrusor muscle relaxation and administration of NOS inhibitors decreases bladder capacity and increases magnitude of bladder contractions (Ho, 2004). Mice lacking nNOS have large bladders-- which are typically observed in urinary 
obstruction or diabetes (Burnett et al, 1997). Other studies show increased expression of iNOS in rat and mice bladders after partial outlet obstruction and urinary tract infections (Ho, 2004).

\subsubsection{Neuropeptides}

Neuropeptides involved in lower urinary tract physiology include vasoactive intestinal peptide (VIP), substance P, calcitonin gene related peptide (CGRP), tachykinins, endothelins, angiotensin and enkephalins. Neuropeptides function as transmitters at afferent terminals in the spinal cord and affect urinary bladder function through different actions such as smooth muscle contraction, activation of micturition reflex, maintenance of vascular tone and permeability (Andersson, 1993).

1.4.7.1 Vasoactive intestinal peptide (VIP): Vasoactive intestinal polypeptide, isolated in 1970, is a highly basic 28 amino acid peptide. Nerves containing VIP are found in bladder layers beneath the urothelium and around blood vessels, with the highest concentration being in urethra and trigone (Fahrenkrug and Emson, 1982).VIP binds to two G- protein coupled receptors, VPAC1 and VPAC2 (Andersson, 1993). VIP has varied effects in different species such that in rabbits, it causes relaxation of the detrusor muscle and inhibition of action potential while in rat and guinea pig bladders; it causes contraction whereas no effect is seen in the isolated human bladder smooth muscle tissue. VIP causes relaxation of trigone, bladder neck and urethra in all species (Hoyle, 1994) but the role of VIP in bladder instability or detrusor overactivity is still unclear (Andersson and Arner, 2004).

1.4.7.2 Substance $\mathbf{P}(\mathbf{S P})$ : Substance $P$ is a potent spasmogen found in the suburothelial layer of the urinary bladder (Harrison and Geppetti, 2001). In rat and guinea pig bladders, substance P acts on NK1 receptors and in humans and hamsters, it acts on NK2 receptors. Substance P plays 
an important sensory neurotransmitter role and is involved in the bladder instability because depletion of SP by capsaicin in rat urinary bladder is known to cause urinary retention (Hoyle, 1994).

1.4.7.3 Calcitonin gene related peptide (CGRP): Calcitonin gene related peptide is found in capsaicin- sensitive sensory nerves supplying the urinary bladder. In high concentrations, topically applied CGRP inhibits the micturition reflex in the rat urinary bladder. In pig, guinea pig and rat bladders, CGRP causes relaxation of bladder neck but has no effect on the bladder body (Hoyle, 1994).

1.4.7.4 Prostanoids: Prostanoids including prostaglandins and thromboxanes are synthesized by cyclooxygenases (COX). Two types of COX enzymes exist; one is constitutive COX (COX-1) and the other is inducible $\mathrm{COX}(\mathrm{COX}-2)$. It has been reported that constitutive $\mathrm{COX}(\mathrm{COX}-1)$ is involved in the normal physiological biosynthesis whereas inducible $\mathrm{COX}(\mathrm{COX}-2)$ is activated during inflammation. Prostanoids are generated in detrusor and mucosa by local and physiological factors such as stretching of the detrusor, injuries to the vesical mucosa, nerve stimulation and agents such as ATP and some inflammatory mediators (Andersson, 1993). Prostanoids such as PGF2 $\alpha$, PGE1, PGE2 and thromboxane A2 (TXA2) cause contraction of isolated human and animal bladders. Prostanoids are not usually involved in bladder emptying because contractile responses caused by prostanoids are slower than other neurally mediated responses. Prostanoids applied topically to the mucosal and serosal layers of the urinary bladder stimulate the initiation of the micturition reflex, potentially by having direct effects on capsaicin sensitive afferent nerves or indirectly by tachykinin release which sensitizes bladder afferent nerves (de Groat and Yoshimura, 2001, Andersson, 1993). 


\subsubsection{Sensory afferent pathways}

Sensory nerves are activated upon urinary bladder distention (when the bladder is full) and these nerves convey information to the spinal cord via pelvic and hypogastric afferent axons. Afferent fibers carry impulses to neurons in the dorsal horn of the spinal cord. The pelvic nerve afferents are found in large numbers in the smooth muscle layers and cause initiation of the micturition reflex whereas hypogastric nerve afferents are found in the mucosa and sub mucosa.

The sensory afferents found in the urinary bladder are of two types- myelinated A $\delta$ fibers and unmyelinated $\mathrm{C}$ fibers. Bladder filling is signaled by $\mathrm{A} \delta$ fibers responding to detrusor stretching and convey sensation of fullness. C fibers respond to chemical irritation of the bladder mucosa or cold; in cats they are mostly mechanoinsensitive and termed 'silent fibers' whereas in rats they are volume receptors that do not respond to bladder contraction. Afferent neurons containing various neuropeptides such as SP, CGRP and VIP trigger inflammatory responses.

Micturition involving different voiding reflexes is initiated by activation of the sacral parasympathetic efferent pathway. Reflex activation of the bladder is caused by a spinobulbospinal pathway passing through the pontine micturition centre (PMC) causing activation of the PMC which results in inhibition of storage reflexes (Sugaya, 2005; Andersson, 2002; de Groat and Yoshimura, 2001; Fowler, 2002; Morrison, 1999; de Groat and Yoshimura, 2009; Yoshimura et al, 2008).

\subsection{Urinary bladder dysfunction and urinary incontinence in diabetes}

\subsubsection{Clinical studies: prevalence, incidence and pathophysiology}

Urinary bladder dysfunction is a common but important complication of DM and is well documented in humans, both males and females. Previous studies have reported that DM affects 
around $40-80 \%$ of incontinent patients, with women affected more frequently than men. Diabetic bladder dysfunction leads to a number of debilitating symptoms including urinary incontinence (UI), diabetic cystopathy, progressive bladder paralysis, urinary tract infection, overactive bladder $(\mathrm{OAB})$; these complications are often irreversible. Diabetes related bladder dysfunction mostly results from neuronal injury and/or altered neuronal control because patients often experience impaired sensation of bladder fullness, sphincter related problems, leaks between voids, etc. The diabetic bladder has been described as being flaccid, hypotonic or atonic. End stage bladder failure is accompanied by a 2- 4 fold increase in bladder capacity, enlarged bladder, increased micturition pressure, increased post void residual urine (PVR) and urinary retention. Increased bladder capacity and PVR could be due to a deficiency of nerve growth factor as diabetes affects sensory afferent pathways. Increased risk of nocturia with weak urinary streams is observed in women with type 2 DM (Lee et al, 2007; Ho et al, 2007; Buck et al, 1976; Andersen and Bradley, 1976; Lee et al, 2009; Goldman and Appell, 1999; Lee et al, 2004).

Of all these conditions, women are most affected by UI. Different types of UI exist such as stress urinary incontinence, urge incontinence, overflow incontinence, functional incontinence and mixed urinary incontinence. Urge incontinence is defined as the complaint of involuntary loss of urine with a sudden and strong desire to void which could be related to detrusor over activity. Dysfunction of CNS control on urine storage leads to urge incontinence. Stress incontinence is the involuntary loss of urine due to coughing, sneezing or any other physical activity or exertion and is mainly related to sphincter dysfunction. Overflow incontinence is the loss of urine with over distention of the bladder whereas mixed incontinence is a combination of stress and urge incontinence together (Blaivas, 1997). The general urodynamic parameters of bladder dysfunction in DM are summarized in Table 1-1.

It is well accepted that urinary incontinence is more common in women than men and that the prevalence of UI increases with age (Jackson et al, 2005; Temml et al, 2000). Although 
it is difficult to determine the prevalence of UI because of under reporting, it is known to affect approximately 10- 50\% of women (Parker, 2007; Norton and Brubaker, 2006). Nearly 3.3 million people in Canada suffer from incontinence (Canadian Continence Foundation) and 13 million people in the US have UI. Based on the findings of the National Health and Nutrition Examination Survey of 2001-2002 data, it is estimated that the prevalence of UI depends on the type of UI, age, ethnic background and weight (Minassian et al, 2008). There is limited data on the incidence and prevalence of LUTS/ UI in DM. Diabetes is associated with all subtypes of UI but in the EPINCONT (Epidemiology of incontinence in the county of Nord-Trøndelag) study, the largest survey carried out on incontinence, it was reported that in diabetes, urge incontinence was observed more than stress incontinence (Hannestad et al, 2000). Urinary incontinence significantly impacts the quality of life in women with type $2 \mathrm{DM}$ and can even lead to functional decline and death (Fayyad, 2009; Minassian et al, 2003).

\subsection{Animal models of diabetes}

Animal models of diabetes have been used for many years in an effort to understand the pathogenesis and long- term complications of diabetes. There are two frequently used monogenic models of type $2 \mathrm{DM}$ and obesity: these are the ob/ob and db/db mouse models. The ob/ob mouse originated from an autosomal recessive mutation on chromosome 6 of the C57BL/6J mouse strain with a mutation in the leptin gene (ob gene) whereas the $\mathrm{db} / \mathrm{db}$ mouse model derived from an autosomal recessive mutation on chromosome 4 of the C57BL/6J strain where there was a mutation in the $\mathrm{db}$ gene encoding the leptin receptor. Human leptin is a $16 \mathrm{kDa}$ protein that is mainly synthesized in adipose tissue and secreted into the circulatory system. Leptin acts at the hypothalamus and has effects on appetite, energy expenditure and the neurocrine axes. Leptin functions to regulate the energy availability in peripheral adipose tissue 
by signaling via specific hypothalamic neurons. Leptin deficiency in mice significantly alters the feeding behavior, metabolism and endocrine function resulting in hyperphagia, decreased energy expenditure and obesity. The ob/ob mouse model shows many characteristics of type 2 diabetes including insulin resistance, glucose intolerance, mild hyperglycemia but ob/ob mice are not always diabetic. In contrast, the $\mathrm{db} / \mathrm{db}$ mice consistently show diabetes and are severely hyperglycemic (Srinivasan and Ramarao, 2007; Montague et al, 1997; Farooqi et al, 1999; Wolf, 2002; Sone and Osamura, 2001).

The $d b / d b$ mouse model is a genetic model of non-insulin dependent type $2 \mathrm{DM}$ in which there is a dysfunction in the leptin receptor. These animals develop hyperglycemia as their beta cells are unable to secrete high levels of insulin and with increasing age develop impairment of insulin resistance (McNeill, 1999; Rees and Alcolado, 2004; Chen and Wang, 2004). The mutation in $d b / d b$ mice is due to a G---T point mutation that resulted in the production of abnormally spliced mRNA for the leptin receptor (Chen and Wang, 2004). In $d b / d b$ mice, hyperinsulinemia occurs within 10 days of age, and slight elevations in blood glucose values are seen by 1 month of age (Sharma et al, 2003). The $d b / d b$ mouse model develops hyperglycemia with glucose values $\sim 14 \mathrm{mmol} / \mathrm{L}$ at 6 weeks of age. Blood glucose values increase with age so that when mice are 8 weeks of age blood glucose values are $\sim 28 \mathrm{mmol} / \mathrm{L}$, and when they are 15 16 weeks old blood glucose values are $\sim 30 \mathrm{mmol} / \mathrm{L}$ (Kobayashi et al, 2000). At 6 months of age, body weight and insulin levels begin to decline due to pancreatic cell degeneration. Thus, $d b / d b$ mice are obese, hyperglycemic and insulin resistant (Kobayashi et al, 2000).

\subsubsection{Animal studies of urinary bladder dysfunction \\ Rodent models}

Two rodent models frequently used to study urinary bladder dysfunction in diabetes are the chemically induced streptozotocin (STZ) model and the BB rat model, a genetic model of 
diabetes. The STZ model of diabetes is a well established model for type 1 diabetes and is used frequently to study changes in urinary bladder function. Urodynamic changes observed in humans (increased urine output, atonic bladder, urinary retention, increased frequency of voiding, increased threshold urine volume required for triggering micturition reflex) are also seen in the STZ rat model of diabetes. Bladders of STZ -induced type 1 diabetic rats are hypertrophic with increased collagen content, showing alterations in bladder contractility and polyuria (Daneshgari et al, 2006; Eika et al, 1994, Özturk et al, 1998; Daneshgari et al, 2006).

Other than rat models, mice with STZ-induced diabetes have also been used to study bladder function. Compared to rat models, studying bladder function in mice for bladder research is more challenging as they have very smaller bladders. Though most of the studies in diabetic mice models have concentrated on the urinary tract infection, some recent studies have also focused on urinary bladder dysfunction mainly concentrating on the structural remodeling and functional alterations (Obana et al, 1991; Rosen et al, 2008; Daneshgari et al, 2006; Poladia and Bauer, 2004; Poladia and Bauer, 2005).

\subsection{Therapies and strategies}

There are several options available for the management of diabetic bladder dysfunction and urinary incontinence. Even though the primary goal in the management of diabetes remains the control of blood glucose levels, the Diabetic Control and Complications Trial/ Epidemiology of Diabetes Interventions and Complications Study failed to show any beneficial effects of intensive glycemic control on diabetic bladder dysfunction (Van Den Eeden et al, 2009). Both urinary incontinence and bladder dysfunction in diabetic women are not cured completely owing to either under-reporting of the problems or failure of the pre and post treatment strategies. 
Hence, effective management of incontinence and related problems in women is an important need.

\subsubsection{Life style modification treatments:}

Conservative treatments such as lifestyle changes and education on healthy bladder habits help to improve the symptoms of UI. Lifestyle modifications include changes in diet and fluid intake, eliminating bladder irritants such as caffeine (which has diuretic effects), smoking cessation and weight management. Bladder training such as timed voiding, establishing proper voiding intervals, delayed voiding, maintaining a bladder diary, pelvic floor muscle exercises and behavioral training are also prescribed to patients (Wyman et al, 2009; O'Neil and Gilmour, 2003; Holroyd-Leduc and Straus, 2004).

\subsubsection{Pharmacotherapy:}

Pharmacologic treatments for urinary incontinence depend upon the type of incontinence. Drugs commonly prescribed for both urge incontinence and overactive bladder in diabetic women are oxybutynin and tolterodine which reduce incontinent episodes by $70 \%$ to $85 \%$. Newer drugs include solifenacin and darifenacin. As opposed to this, overflow incontinence is treated by a combination of a muscarinic receptor agonist and $\alpha$ - adrenergic antagonists (Diokno, 2004; Yoshimura and Chancellor, 2002).

\subsubsection{Catheterization:}

Placing an indwelling catheter or using intermittent catheterization is frequently helpful in the treatment of bladder dysfunction and incontinence. Indwelling catheterization is used as a last resort as it can lead to complications such as infection, septic episodes, urethral trauma, bleeding, bladder stones and carcinomas (Newman, 2007). 


\subsubsection{Surgery:}

Surgery is usually recommended when none of the other treatments are effective. Detrusor overactivity is treated by neuromodulation. Detrusor myomectomy or bladder augmentation can be performed to reduce detrusor contraction. Ileal conduit urinary diversion is performed on patients to improve continence (Santiagu et al, 2008).

\subsection{Mechanisms of diabetic bladder dysfunction and urinary incontinence}

The mechanisms underlying diabetes induced bladder dysfunction and urinary incontinence are still unknown although hyperglycemia is known to lead to polyuria and detrusor instability. Diabetes is associated with microvascular damage and that leads to alterations in detrusor smooth muscle function and changes in bladder innvervation. Microvascular complications in diabetes can damage neurologic innervation of the sphincter muscle. Other important factors in diabetic incontinence are severity of diabetes and extent of peripheral neuropathy (Brown et al, 2003). Diabetic patients have higher body mass index (BMI), which will lead to increases in abdominal pressure, bladder pressure and urethral mobility. Increased urinary retention and post void volume leads to overflow incontinence and urinary tract infections, commonly seen in diabetic women (Jackson et al, 2005).

\subsubsection{Polyuria}

Polyuria frequently occurs during diabetes and causes decreased bladder sensation, increased bladder capacity and voiding frequency and eventually leads to hypertrophy of the urinary bladder (Mizusawa et al, 2006; Beshay and Carrier, 2004). 


\subsubsection{Neuropathy}

Early diabetes causes neuropathy in diabetic patients which leads to disruption of nerve supply to lower urinary tract, causing decreased bladder sensation, increased involuntary bladder contractions and altered urethral function (Ho et al, 2007). Diabetic neuropathy leads to segmental demyelination and impaired nerve conduction and deficiency of axonal nerve growth factor (Yoshimura et al, 2005; Smith, 2006).

\subsubsection{Smooth muscle dysfunction}

Diabetes induced hypertrophy of the urinary bladder smooth muscle may be due to polyuria but the exact mechanism is still unknown. It has been reported that diabetes causes alterations in bladder tissue composition, compliance and detrusor function. Hyperglycemia also causes changes in the neurogenically mediated contractile pathways in the detrusor smooth muscle (Ho et al, 2007).

\subsubsection{Cholinergic and adrenergic receptor alterations}

Cholinergic, adrenergic and NANC mechanisms are important in the regulation of urinary bladder function. Bladder contraction is mainly mediated by activation of muscarinic component whereas bladder relaxation occurs via activation of beta receptors. Studies in STZ induced type 1 diabetic models report increased muscarinic receptor density (Latifpour et al, 1988), which was later shown to be due to a $54 \%$ increase in the expression of the M3 receptors in the urothelium and bladder muscle, suggesting that both motor and sensory function of bladder are affected by diabetes (Cheng, 2007). 


\subsection{Exercise and diabetes mellitus}

Exercise training is routinely recommended as a strategy in the management of diabetes mellitus. Regular exercise training in diabetic patients helps to improve the cardiac function with decreased susceptibility to arrhythmias. Studies in animal models of diabetes report that exercise improves glucose metabolism in cardiac muscle as well improving myocardial glucose metabolism (Broderick, 2005) and improving insulin sensitivity and decreases triglycerides and total cholesterol (Hagey and Warren, 2008; Li et al, 2003; Knowler et al, 2002).

Several studies have examined the effects of exercise on endothelial dysfunction in diabetes. Exercise decreases oxidative stress by reducing free radical generation, which is a common feature of diabetes. Exercise also improves the cognitive function of the brain which may be of additional benefit in diabetic mice (Stranahan et al, 2009). Studies to date have concentrated on the cardiovascular benefits of exercise in diabetes but the effects of exercise on bladder dysfunction and incontinence in diabetic patients or animals have not been studied.

\subsection{Hypothesis}

Urinary incontinence in diabetes is a well recognized phenomenon but the treatment strategies employed are not effective in treating the condition. None of the treatments available concentrate on early preventive measures in diabetes. Exercise is considered a corner stone in the management of type 2 diabetes and beneficial effects of exercise are clear in human and animal models of diabetes. In this thesis, we hypothesize that exercise improves urinary bladder dysfunction and urinary incontinence in diabetic mice. 


\subsubsection{Thesis objectives}

1) Investigate the voiding function of $d b / d b$ mice

2) Explore the effects of exercise on the voiding frequency of $d b / d b$ mice

3) Study the effects of exercise on the urodynamic parameters of $d b / d b$ mice

4) Compare the contractility of isolated bladder strips in exercised and non- exercised $\mathrm{db} / \mathrm{db}$ mice. 


\begin{tabular}{|c|c|c|c|}
\hline No. & $\begin{array}{l}\text { Urodynamic parameters } \\
\text { affected in diabetes }\end{array}$ & Change & References \\
\hline 1 & Bladder capacity & Increase & \multirow{4}{*}{$\begin{array}{l}\text { Lee et al, 2007; Ho et al, 2007; Buck } \\
\text { et al, 1976; Andersen and Bradley, } \\
\text { 1976; Lee et al, 2009; Goldman and } \\
\text { Appell, } 1999\end{array}$} \\
\hline 2 & Post void residual urine & Increase & \\
\hline 3 & Micturition pressure & Increase & \\
\hline 4 & Bladder compliance & Increase & \\
\hline
\end{tabular}

Table 1-1: General urodynamic parameters affected in diabetes 


\subsection{Bibliography}

Andersen JT, Bradley WE (1976) Abnormalities of bladder innervation in diabetes mellitus. Urology, 7 (4): 442- 448.

Anderson KE (1993) Pharmacology of lower urinary tract smooth muscles and penile erectile tissues. Pharmacol Rev, 45 (3): 253-308.

Andersson KE (1999) Advances in the pharmacological control of the bladder. Exp Physiol, 84 (1): $195-213$.

Andersson KE (2002) Bladder activation: afferent mechanisms. Urology, 59 (5 Suppl 1): 43-50.

Andersson KE, Arner A (2004) Urinary bladder contraction and relaxation: physiology and pathophysiology. Physiol Rev, 84 (3): 935- 986.

Belis JA, Curley RM, Lang CM (1996) Bladder dysfunction in the spontaneously diabetic male Abyssinian-Hartley guinea pig. Pharmacology, 53 (1): 66-70.

Beshay E, Carrier S (2004) Oxidative stress plays a role in diabetes-induced bladder dysfunction in a rat model. Urology, 64 (5): 1062-1067.

Birder LA (2005) More than just a barrier: urothelium as a drug target for urinary bladder pain. Am J Physiol Renal Physiol, 289 (3): F489-95. 
Blaivas JG, Appell RA, Fantl JA, Leach G, McGuire EJ, Resnick NM, Raz S, Wein AJ (1997)

Definition and classification of urinary incontinence: recommendations of the Urodynamic Society. Neurourol Urodyn, 1997; 16 (3): 149-151.

Boyle JP, Honeycutt AA, Narayan KM, Hoerger TJ, Geiss LS, Chen H, Thompson TJ (2001)

Projection of diabetes burden through 2050: impact of changing demography and disease prevalence in the U.S. Diabetes Care, 24 (11): 1936-1940.

Broderick TL, Poirier P, Gillis M (2005) Exercise training restores abnormal myocardial glucose utilization and cardiac function in diabetes. Diabetes Metab Res Rev, 21 (1): 44- 50.

Brown JS, Nyberg LM, Kusek JW, Burgio KL, Diokno AC, Foldspang A, Fultz NH, Herzog AR, Hunskaar S, Milsom I, Nygaard I, Subak LL, Thom DH (2003) National Institute of Diabetes and Digestive Kidney Diseases International Research Working Group on Bladder Dysfunction Proceedings of the National Institute of Diabetes and Digestive and Kidney Diseases International Symposium on Epidemiologic Issues in Urinary Incontinence in Women. Am J Obstet Gynecol, 188 (6): S77- 88.

Buck AC, Reed PI, Siddiq YK, Chisholm GD, Fraser TR (1976) Bladder dysfunction and neuropathy in diabetes. Diabetologia, 12 (3): 251- 258.

Burnett AL, Calvin DC, Chamness SL, Liu JX, Nelson RJ, Klein SL, Dawson VL, Dawson TM, Snyder SH (1997) Urinary bladder-urethral sphincter dysfunction in mice with targeted disruption of neuronal nitric oxide synthase models idiopathic voiding disorders in humans. Nat Med, 3 (5): 571- 574. 
Canadian Diabetes Association. 2007, Ref type: Electronic citation.

http://www.diabetes.ca/about-diabetes/what/history/

Canadian Diabetes Association. 2007a, Ref type: Electronic citation.

http://www.diabetes.ca/about-diabetes/what/prevalence/

Chen D, Wang MW (2005) Development and application of rodent models for type 2 diabetes. Diabetes Obes Metab, 7 (4): 307- 317.

Choppin A (2002) Muscarinic receptors in isolated urinary bladder smooth muscle from different mouse strains. Br J Pharmacol, 137 (4): 522-528.

Daneshgari F, Huang X, Liu G, Bena J, Saffore L, Powell CT (2006) Temporal differences in bladder dysfunction caused by diabetes, diuresis, and treated diabetes in mice. Am J Physiol Regul Integr Comp Physiol, 290 (6): R1728-1735.

Daneshgari F, Liu G, Imrey PB (2006) Time dependent changes in diabetic cystopathy in rats include compensated and decompensated bladder function. J Urol, 176 (1): 380-386.

Deshpande AD, Harris-Hayes M, Schootman M (2008) Epidemiology of diabetes and diabetesrelated complications. Phys Ther; 88: 1254-1264.

de Groat WC (2004) The urothelium in overactive bladder: passive bystander or active participant Urology, 64 (6 Suppl 1): 7-11. 
de Groat WC, Yoshimura N (2001) Pharmacology of the lower urinary tract Annu Rev Pharmacol Toxicol, 41: 691-721.

Diokno AC (2004) Medical management of urinary incontinence. Gastroenterology, 126(1 Suppl 1): $\mathrm{S} 77-81$.

Eknoyan G, Nagy J (2005) A history of diabetes mellitus or how a disease of the kidneys evolved into a kidney disease. Adv Chronic Kidney Dis, 12 (2): 223-229.

Eika B, Levin RM, Longhurst PA (1994) Comparison of urinary bladder function in rats with hereditary diabetes insipidus, streptozotocin-induced diabetes mellitus, and non- diabetic osmotic diuresis. Urol, 151 (2): 496-502.

Farooqi IS, Jebb SA, Langmack G, Lawrence E, Cheetham CH, Prentice AM, Hughes IA, McCamish MA, O'Rahilly S (1999) Effects of recombinant leptin therapy in a child with congenital leptin deficiency. $N$ Engl J Med, 341 (12): 879- 884.

Fayyad AM, Hill SR, Jones G (2009) Prevalence and risk factors for bothersome lower urinary tract symptoms in women with diabetes mellitus from hospital-based diabetes clinic. Int Urogynecol J Pelvic Floor Dysfunct, [Epub ahead of print].

Fowler CJ (2002) Bladder afferents and their role in the overactive bladder. Urology, 59 (5 Suppl 1): $37-42$. 
Fahrenkrug J, Emson PC (1982) Vasoactive intestinal polypeptide: functional aspects. $\mathrm{Br} \mathrm{Med}$ Bull, 38 (3): 265- 270.

Gray MA, Wang CC, Sacks MS, Yoshimura N, Chancellor MB, Nagatomi J (2008) Timedependent alterations of select genes in streptozotocin-induced diabetic rat bladder. Urology, 71 (6): 1214- 1219.

Goldman HB, Appell RA (1999) Voiding dysfunction in women with diabetes mellitus. Int Urogynecol J Pelvic Floor Dysfunct, 10 (2): 130-133.

Hagey AR, Warren MP (2008) Role of exercise and nutrition in menopause. Clin Obstet Gynecol, 51 (3): 627- 641.

Hannestad YS, Rortveit G, Sandvik H, Hunskaar S (2000) Norwegian EPINCONT study. Epidemiology of Incontinence in the County of Nord-Trøndelag. A community-based epidemiological survey of female urinary incontinence. Clin Epidemiol, 53 (11): 1150-1157.

Harris, M (2004) Definition and Classification of Diabetes Mellitus and the criteria for diagnosis. Diabetes Mellitus: A Fundamental and Clinical Text (ed. by D. LeRoith, S. I. Taylor, \& J. M. Olefsky), pp. 457-467. Lippincott Williams \& Wilkins, Philadelphia.

Harrison S, Geppetti P (2001) Substance P. Int J Biochem Cell Biol, 33 (6): 555-576. 
Hedlund P (2005) Nitric oxide/cGMP-mediated effects in the outflow region of the lower urinary tract--is there a basis for pharmacological targeting of cGMP? World J Urol, 23 (6): 362-367.

Ho MH, Bhatia NN, Khorram O (2004) Physiologic role of nitric oxide and nitric oxide synthase in female lower urinary tract. Curr Opin Obstet Gynecol, 6 (5): 423-429.

Ho MH, Yip S, Bhatia NN (2007) Lower urinary tract dysfunctions in women with diabetes mellitus. Curr Opin Obstet Gynecol, 19 (5): 469-473.

Holroyd-Leduc JM, Straus SE (2004) Management of urinary incontinence in women: scientific review. JAMA, 291 (8): 986- 995.

Hoyle CH (1994) Non-adrenergic, non-cholinergic control of the urinary bladder. World J Urol, 12 (5): 233- 244.

Ichiyanagi N, Tsujii T, Masuda H, Kihara K, Goto M, Azuma H (2002) Changed responsiveness of the detrusor in rabbits with alloxan induced hyperglycemia: possible role of 5hydroxytryptamine for diabetic bladder dysfunction. Urol, 168 (1): 303- 307.

Jackson SL, Scholes D, Boyko EJ, Abraham L, Fihn SD (2005) Urinary incontinence and diabetes in postmenopausal women. Diabetes Care, 28 (7): 1730- 1738.

Parker K (2007) The management of Urinary Incontinence Drug topics, Vol 51/18, 69-78. 
Knowler WC, Barrett-Connor E, Fowler SE, Hamman RF, Lachin JM, Walker EA, Nathan DM; Diabetes Prevention Program Research Group (2002) Reduction in the incidence of type 2 diabetes with lifestyle intervention or metformin. Engl J Med, 346 (6): 393- 403

Kobayashi K, Forte TM, Taniguchi S, Ishida BY, Oka K, Chan L (2000) The db/db mouse, a model for diabetic dyslipidemia: molecular characterization and effects of Western diet feeding. Metabolism, 49 (1): 22-31.

Kung HC, Hoyert DL, Xu J, Murphy SL (2008) Deaths: final data for 2005. Natl Vital Stat Rep., 56 (10): 1-120.

Latifpour J, Gousse A, Kondo S, Morita T, Weiss RM (1988) Effects of experimental diabetes on biochemical and functional characteristics of bladder muscarinic receptors. J Pharmacol Exp Ther, 248 (1): $81-88$.

Lee WC, Wu HP, Tai TY, Liu SP, Chen J, Yu HJ (2004) Effects of diabetes on female voiding behavior. J Urol, 172 (3): 989- 992.

Lee WC, Wu CC, Wu HP, Tai TY (2007) Lower urinary tract symptoms and uroflowmetry in women with type 2 diabetes mellitus with and without bladder dysfunction. Urology, 69 (4): 685- 690 . 
Lee WC, Wu HP, Tai TY, Yu HJ, Chiang PH (2009) Investigation of urodynamic characteristics and bladder sensory function in the early stages of diabetic bladder dysfunction in women with type 2 diabetes. $J$ Urol, 181(1): 198- 203.

Lewis SA (2000) Everything you wanted to know about the bladder epithelium but were afraid to ask. Am J Physiol Renal Physiol, 278 (6): F867- 74.

Li S, Culver B, Ren J (2003) Benefit and risk of exercise on myocardial function in diabetes. Pharmacol Res, 48 (2): 127- 132.

Longhurst PA, Uvelius B (2001) Pharmacological techniques for the in vitro study of the urinary bladder. J Pharmacol Toxicol Methods, 45 (2): 91-108.

Mannikarottu AS, Changolkar AK, Disanto ME, Wein AJ, Chacko S (2005) Over expression of smooth muscle thin filament associated proteins in the bladder wall of diabetics. J Urol, 174 (1): $360-364$.

Michel M., Oelke M, Peters S (2005) The Neuro-Urological Connection European Urology Supplements, Volume 4, Issue 1, Pages 18- 28.

Minassian VA, Drutz HP, Al-Badr A (2003) Urinary incontinence as a worldwide problem. Int J Gynaecol Obstet, 82 (3): 327- 338.

Minassian VA, Stewart WF, Wood GC (2008) Urinary incontinence in women: variation in prevalence estimates and risk factors. Obstet Gynecol, 111 (2 Pt 1): 324-331. 
Mizusawa H, Ishizuka O, Igawa Y, Komiyama M, Irie K, Iwata K, Nishizawa O (2006)

Improvement of polyuria, bladder sensation and bladder capacity following renal transplantation. Int J Urol, 13 (5): 616- 618.

Morrison J (1999) The activation of bladder wall afferent nerves. Exp Physiol, 84 (1): 131-136.

Montague CT, Farooqi IS, Whitehead JP, Soos MA, Rau H, Wareham NJ, Sewter CP,

Digby JE, Mohammed SN, Hurst JA, Cheetham CH, Earley AR, Barnett AH, Prins JB, O'Rahilly

S (1997) Congenital leptin deficiency is associated with severe early-onset obesity in humans.

Nature, 26; 387 (6636): 903- 908.

Mumtaz FH, Thompson CS, Khan MA, Mikhailidis DP, Morgan RJ, Angelini GD, Jeremy JY (1999) Alterations in the formation of cyclic nucleotides and prostaglandins in the lower urinary tract of the diabetic rabbit. Urol Res, 27 (6): 470- 475.

Newman DK (2007) The indwelling urinary catheter: principles for best practice. $J$ Wound Ostomy Continence Nurs, 34 (6): 655- 661.

Newman DK, Wein A (2009) Managing and treating urinary incontinence, Health profession press Forewords by Diana J. Mason and Joseph G. Ouslander.

Norton P, Brubaker L. Urinary incontinence in women (2006) Lancet, 367 (9504): 57- 67. 
Obana Y, Shibata K, Nishino T (1991) Adherence of Serratia marcescens in the pathogenesis of urinary tract infections in diabetic mice. J Med Microbiol, 35 (2): 93- 97.

O'Neil B, Gilmour D (2003) Approach to urinary incontinence in women. Diagnosis and management by family physicians. Can Fam Physician, 49: 611- 618.

Ouslander JG (2004) Management of overactive bladder. N Engl J Med ,19, 350 (8): 786- 799.

Özturk Y., Altan M V., Ari N (1998) Diabetic Complications in Experimental Models Tr. J. of Medical Sciences, 22, 331- 341.

Poladia DP, Bauer JA (2004) Oxidant driven signaling pathways during diabetes: role of Rac1 and modulation of protein kinase activity in mouse urinary bladder. Biochimie, 86 (8): 543- 551.

Poladia DP, Bauer JA (2005) Functional, structural, and neuronal alterations in urinary bladder during diabetes: investigations of a mouse model. Pharmacology, 74 (2): 84- 94.

Rees DA, Alcolado JC (2005) Animal models of diabetes mellitus. Diabet Med, 22 (4): 359370.

Roberts MM (2008) Neurophysiology in neurourology. Muscle Nerve, 38 (1): 815- 836.

Rosen DA, Hung CS, Kline KA, Hultgren SJ. Streptozocin-induced diabetic mouse model of urinary tract infection. Infect Immun, 76 (9): 4290- 4298. 
Santiagu SK, Arianayagam M, Wang A, Rashid P (2008) Urinary incontinence-pathophysiology and management outline. Aust Fam Physician, 37 (3): 106-110.

Sharma K, McCue P, Dunn SR (2003) Diabetic kidney disease in the db/db mouse. Am J Physiol Renal Physiol, 284 (6): F 1138- 1144.

Smith DB (2006) Urinary incontinence and diabetes: a review. J Wound Ostomy Continence Nurs, 33 (6): 619- 623.

Sone M, Osamura RY (2001) Leptin and the pituitary. Pituitary, 4 (1-2): 15-23.

Srinivasan K, Ramarao P (2007) Animal models in type 2 diabetes research: an overview. Indian J Med Res, 125 (3): 451- 472.

Steers WD (1992) Physiology of the urinary bladder In: Walsh PC, Retik AB, Stamey TA, Vaughn E Jr (Eds) Campbell's Urology, 6th edn. Philadephia: Saunders.

Stengel PW, Yamada M, Wess J, Cohen ML (2002) M (3)-receptor knockout mice: muscarinic receptor functions in atria, stomach fundus, urinary bladder, and trachea. Am J Physiol Regul Integr Comp Physiol, 282 (5): R1443-1449.

Stratton IM, Adler AI, Neil HA, Matthews DR, Manley SE, Cull CA, Hadden D, Turner RC, Holman RR (2000) Association of glycaemia with macrovascular and microvascular complications of type 2 diabetes (UKPDS 35): prospective observational study. BMJ, 321 (7258): 405- 412. 
Sugaya K, Nishijima S, Miyazato M, Ogawa Y (2005) Central nervous control of micturition and urine storage. J Smooth Muscle Res, 41 (3): 117-132.

Temml C, Haidinger G, Schmidbauer J, Schatzl G, Madersbacher S (2000) Urinary incontinence in both sexes: prevalence rates and impact on quality of life and sexual life. Eurourol Urodyn., 19 (3): 259- 271.

Van Den Eeden SK, Sarma AV, Rutledge BN, Cleary PA, Kusek JW, Nyberg LM, McVary KT, Wessells H (2009)Diabetes Control and Complications Trial/Epidemiology of Diabetes Research Group. Effect of intensive glycemic control and diabetes complications on lower urinary tract symptoms in men with type 1 diabetes: Diabetes Control and Complications Trial/Epidemiology of Diabetes Interventions and Complications (DCCT/EDIC) study. Diabetes Care, 32 (4): 664670.

Wang CC, Nagatomi J, Toosi KK, Yoshimura N, Hsieh JH, Chancellor MB, Sacks MS (2009) Diabetes-induced alternations in biomechanical properties of urinary bladder wall in rats. Urology; 73 (4): 911- 915.

Wiseman OJ, Brady CM, Hussain IF, Dasgupta P, Watt H, Fowler CJ, Landon DN (2002) The ultrastructure of bladder lamina propria nerves in healthy subjects and patients with detrusor hyperreflexia. J Urol, 168 (5): 2040- 2045.

Wolf G, Chen S, Han DC, Ziyadeh FN (2002) Leptin and renal disease. Am J Kidney Dis, 39 (1): $1-11$. 
Wyman JF, Burgio KL, Newman DK (2009) Practical aspects of lifestyle modifications and behavioural interventions in the treatment of overactive bladder and urgency urinary incontinence. Int J Clin Pract, 63 (8): 1177- 1191.

Yoshimura N, Chancellor MB (2002) Current and future pharmacological treatment for overactive bladder. Uro, 168 (5): 1897- 1913.

Yoshimura N, Chancellor MB, Andersson KE, Christ GJ (2005) Recent advances in understanding the biology of diabetes-associated bladder complications and novel therapy. $B J U$ Int; 95 (6): 733- 738.

Yoshimura N, Kaiho Y, Miyazato M, Yunoki T, Tai C, Chancellor MB, Tyagi P (2008) Therapeutic receptor targets for lower urinary tract dysfunction. Naunyn Schmiedebergs Arch Pharmacol, 377 (4-6): 437- 448. 


\section{EXERCISE IMPROVES BLADDER FUNCTION IN DIABETIC}

MICE

A version of this chapter has been submitted for publication. Vadhavkar M, Sea J, Laher I, Stothers L. Exercise improves bladder dysfunction in diabetic mice. 


\subsection{Introduction}

Diabetes Mellitus (DM) is the most prevalent medical disorder today with type 2 diabetes accounting for more than $90 \%$ of cases (Srinivasan et al, 2008). Sequalae of diabetes can involve multiple organ systems and include neuropathy, nephropathy, cardiovascular and opthalmologic complications. Urologic complications arising from diabetes include urinary bladder dysfunction, a serious complication of type $2 \mathrm{DM}$ which may manifest as urinary incontinence (UI), infection and impaired bladder emptying leading to retention of urine and loss of sensation in patients. The progression of bladder dysfunction begins with bladder hyperactivity, progressing to incontinence and eventually results in end stage cystopathy (Brown et al, 2005). Urinary incontinence represents a complaint of any involuntary leakage of urine (Abrams et al, 2003). The prevalence of UI is difficult to determine due to under- reporting but is estimated to involve approximately 13 million Americans and around 3 million Canadians (Canadian Foundation of Urinary Incontinence, 2006).

In diabetes, urge incontinence is more common than stress incontinence. Both, pharmacological and non- pharmacological modalities are available as treatment options to patients suffering from urinary incontinence (Kebapci et al, 2007; Danforth et al, 2009). Nonpharmacological interventions include Kegel exercises, biofeedback, electrical stimulation, bladder training, management of fluid intake, elimination of the bladder irritants from the diet such as caffeine, carbonated drinks and timed voiding(O' Neil and Gilmour, 2003; Wyman et al, 2009). However, the effectiveness of early preventive measures for the regulation of diabetic UI has not been studied.

Exercise is the initial recommended management strategy for diabetes, but its implications in diabetic UI are unknown (Duncan, 2006). In this study we examine the effects of moderate intensity exercise on bladder function in diabetes. We hypothesize that moderate exercise improves diabetic bladder function in type 2 diabetes by reducing voiding frequency. 
We used the $d b / d b$ mouse model that has mutations in the leptin receptor and has many features found in human type 2 DM (Srinivasan and Ramarao, 2007; McIntosh and Pederson, 1999).

\subsection{Materials and methods}

\subsubsection{Drugs and solutions}

Carbachol was purchased from Sigma Company (St. Louis, MO, USA). Physiological salt solution (PSS) was prepared fresh daily and had following composition (in $\mathrm{mM}$ ): $\mathrm{NaCl} 119, \mathrm{KC} 1$ 4.7, $\mathrm{MgSO}_{4} 7 \mathrm{H}_{2} \mathrm{O} 1.17, \mathrm{NaHCO}_{3} 24, \mathrm{CaCl}_{2}$ 21.6, $\mathrm{KH}_{2} \mathrm{PO} 41.18$, glucose 11.1, EDTA 0.024. Solutions rich in potassium chloride $(\mathrm{KCl})$ were prepared by equimolar replacement of $\mathrm{NaCl}$ with $\mathrm{KCl}$.

\subsubsection{Animals}

All experimental procedures were approved by the Animal Care Committee of the University of British Columbia (Certificate Number A06- 0277). Thirty two $d b / d b$ female mice (BKS. Cg$\mathrm{m}+/+\operatorname{Lepr}^{\mathrm{db}} / \mathrm{J}$ strain) and their age matched wild type controls (WT) were purchased from Jackson Laboratories (Bar Harbor, MA). Mice were housed under standard animal room conditions having 12 hour light/dark cycles and a temperature of $26^{\circ} \mathrm{C}$, with free access to food and water. Diabetic $(d b / d b)$ and wild type (WT) mice were randomly divided into equal groups of exercised (Ex) and sedentary (no exercise) animals.

\subsubsection{Exercise protocol}

Diabetic $(d b / d b)$ and wild- type (WT) mice (6 weeks old) assigned to the exercise protocol were trained to run on a motorized exercise wheel system (Lafayette Instrument Co, Indiana, USA) for 
8 weeks. The extent of exercise was increased incrementally for the first two weeks to allow for acclimatization. The initial exercise speed was 2.5 meters/min for one hour per day and this was gradually increased to a speed of 5.2 meters/ min per day which remained constant for the remainder of the exercise protocol. Mice were exercised daily, five days per week for 8 weeks at a set time each day. Sedentary animals were placed in the non- rotating wheels for the same duration as the exercised mice (Moien-Afshari et al, 2008). The exercise protocol for mice is shown in the Table 2-1. Body weight was recorded every week. Blood glucose values were measured on a weekly basis obtained through the caudal vein using a blood glucose monitoring system (Ascensia Contour, Bayer Healthcare).

\subsubsection{Pad test}

To study the voiding pattern and frequency of mice, a pad test was performed based on previous descriptions (Cornelissen et al, 2008; Liang et al, 2002). Both $d b / d b$ and WT mice were placed in metabolic cages (one mouse per cage) with free access to food and water. The metabolic cages were free of bedding. Large sheets of filter paper (measuring $26 \mathrm{~cm} \times 15 \mathrm{~cm}$ ) were placed on the floor of each cage (Whatman Grade 470, VWR). Mice were kept in the cages overnight for 12 hours (water and food ad libitum) so that there was minimal human interaction. Urine spots on the filter paper were identified and the pattern and frequency of voiding determined.

\subsubsection{Animal surgery}

Surgical implantation of bladder catheters was performed prior to cystometry. Mice were catheterized using previously described techniques (Aboushwareb et al, 2009). Mice were anesthetized by intraperitoneal injection of ketamine $(80 \mathrm{mg} / \mathrm{kg})$ and xylazine $(10 \mathrm{mg} / \mathrm{kg})$ and the ventral abdominal wall and upper back shaved. A mid-line longitudinal incision was made $0.5 \mathrm{~cm}$ above the urethral meatus. The bladder was identified, exposed and a purse string suture 
using 6-0 silk was placed through the bladder wall at the dome of the bladder. A small incision was then made in the bladder wall using micro-dissecting scissors and BCo-Ex T25 tubing with a cuff (Instech Solomon Laboratories, PA) was implanted. The 6-0 silk suture was tightened around the catheter to anchor it and close the bladder incision. Saline was injected through the catheter to ensure that there was no bladder leakage and to confirm patency. The catheter was then tunneled through the subcutaneous space and externalized through an orifice at the back of the neck of the animal. This tubing was then secured with suture and surgical tape. The incisions were closed separately using 6-0 vicryl sutures. The free end of the catheter was thermally sealed to avoid infection. The surgical procedure was performed under sterile conditions.

\subsubsection{Cystometry}

Cystometric analysis was performed as described previously (Aboushwareb et al, 2009). Mice were placed in metabolic cages and cystometry was performed for a period of 2-3 hours. A filled $10 \mathrm{ml}$ syringe was placed on an infusion pump and an infusion rate $(1.5 \mathrm{ml} /$ hour for mice $)$ was used. The implanted bladder catheter exiting from the neck was connected via a two way valve attached to a pressure transducer and an infusion pump. The pressure transducer was connected via an ETH 400 (CB sciences) transducer to a Maclab data acquisition board (Power Lab). The pressure transducer $\left(\mathrm{cmH}_{2} \mathrm{O}\right)$ was calibrated before each experiment. Room temperature saline was infused into each bladder at a rate of $1.5 \mathrm{ml} /$ hour. Voided urine was collected in a tube coated with silicone and attached to a force displacement transducer. Both the transducers were connected to an amplifier and acquisition software was used to record the data. Intravesical pressure and micturition volume were continuously recorded. Data was analyzed after the voiding pattern of the mice became stable and consistent. 


\subsubsection{Pharmacological response measurements}

Individual rectangular mouse bladder strips were mounted in water- jacketed organ bath chambers containing PSS aerated with carbogen $\left(95 \% \mathrm{O}_{2}\right.$ and $\left.5 \% \mathrm{CO}_{2}\right)$. The temperature of the organ bath was maintained at $37^{\circ} \mathrm{C}$. Bladder strips were allowed to equilibrate for 60 minutes and subjected to a $1 \mathrm{~g}$ baseline tension. During this time, the PSS was replaced at 10-minute intervals. A cumulative concentration response curve (CRC) of $\mathrm{KCl}(8 \mathrm{mM}-127 \mathrm{mM})$ was then constructed, after which the strips were washed several times until the tension returned to baseline values. The strips were then subjected to a CRC to carbachol (CCh) $\left(10^{-9}\right.$ to $\left.10^{-4} \mathrm{M}\right)$.

The contractile response of the bladder strips by carbachol was calculated as:

Tension at contraction at a given concentration of CCh - Resting tension/ Tension at maximum response to CCh-Resting tension $\mathrm{x} 100$.

The maximum contraction response (CCh-induced contraction) of the bladder strips by KCl was calculated as:

Tension at contraction at the given concentration of CCh- Resting tension (CCh)/ Tension at maximum response to $\mathrm{KCl}-$ Resting tension $(\mathrm{KCl}) \times 100$.

\subsubsection{Statistical data analysis and calculations}

Results are expressed as mean \pm SEM. Comparisons were made using repeated measures ANOVA with multiple comparisons with Bonferroni's test and one-way ANOVA where required. Results with $\mathrm{P}<0.05$ are considered significant. Analysis of concentration response curves was made using GraphPad Prism software (GraphPad Prism 4, Version 4.00). 


\subsection{Results}

\subsubsection{Body weight}

Body weights of $d b / d b$ and WT mice were measured on a weekly basis and are shown in the Figure 2-1.

Sedentary group: At 6 weeks of age, diabetic $(d b / d b)$ mice had a mean body weight of $29.0 \pm$ 0.7 gm vs. wild type (WT) $17.4 \pm 0.5 \mathrm{gm}(\mathrm{n}=8$ in each group). At 12 weeks of age, diabetic $(\mathrm{db} / \mathrm{db})$ mice had body weights of $46.0 \pm 0.9$ gm vs. wild type (WT) $22.7 \pm 0.7 \mathrm{gm}$. At the time of sacrifice at 16 weeks, diabetic $(d b / d b)$ mice had body weights of $46.1 \pm 0.8$ gm while WT mice had body weights of $23.8 \pm 0.9$ gm $(\mathrm{P}<0.01$, repeated measures ANOVA).

Exercise group: At 6 weeks of age, exercised diabetic $(\mathrm{db} / \mathrm{db})$ mice had body weights of $30.5 \pm$ 0.6 gm vs. wild type (WT) mice $16.1 \pm 0.4 \mathrm{gm}$. At 12 weeks of age, $d b / d b$ - ex mice had body weights of $43.3 \pm 1.2 \mathrm{gm}$ whereas WT- ex mice had body weights of $19.0 \pm 0.4 \mathrm{gm}$. At the time of sacrifice, 16 weeks, diabetic $(d b / d b)$ ex mice had body weights of $43.4 \pm 2.2$ gm vs. WT- ex mice had body weights of $22.0 \pm 0.9 \mathrm{gm}$.

\subsubsection{Blood glucose}

Blood glucose of $d b / d b$ and WT mice were measured on a weekly basis and are shown in the Figure 2-2.

Sedentary group: At 6 weeks of age, $d b / d b$ mice had blood glucose values of $19.6 \pm 2.2$ $\mathrm{mmol} / \mathrm{L}$ vs. wild type (WT) mice $5.9 \pm 0.14 \mathrm{mmol} / \mathrm{L}(\mathrm{n}=8$ in each group). When mice were 12 weeks of age, diabetic $(\mathrm{db} / \mathrm{db})$ mice had blood glucose levels of $31.2 \pm 0.3 \mathrm{mmol} / \mathrm{L}$ while the WT mice had blood glucose levels of $6.4 \pm 0.1 \mathrm{mmol} / \mathrm{L}$. Mice were sacrificed at 16 weeks of age, at which time the blood glucose values were $31.9 \pm 0.3 \mathrm{mmol} / \mathrm{L}$ in $d b / d b$ mice while those in WT 
was $6.1 \pm 0.1 \mathrm{mmol} / \mathrm{L}(\mathrm{P}<0.01$, repeated measures ANOVA). The blood glucose values of the diabetic $(d b / d b)$ and WT sedentary mice are shown in the Figure 2-2.

Exercise group: At 6 weeks of age, blood glucose in exercised $d b / d b$ mice was $23.0 \pm 1.3$ $\mathrm{mmol} / \mathrm{L}$ where as in exercised WT mice blood glucose levels were $5.3 \pm 0.2 \mathrm{mmol} / \mathrm{L}$. At 12 weeks, $d b / d b$-ex mice had blood glucose levels of $29.9 \pm 0.8 \mathrm{mmol} / \mathrm{L}$ while in WT- ex mice, blood glucose levels were $5.7 \pm 0.2 \mathrm{mmol} / \mathrm{L}$. At the time of sacrifice (16 weeks), $d b / d b$ - ex mice had blood glucose levels of $30.6 \pm 0.5 \mathrm{mmol} / \mathrm{L}$ while WT- ex mice had blood glucose levels of $5.2 \pm 0.2 \mathrm{mmol} / \mathrm{L}$

\subsubsection{Voiding pattern and frequency}

Following eight weeks of exercise, when mice were aged 16 weeks, $d b / d b$ sedentary mice had a voiding frequency of $10.8 \pm 1.1$ whereas $d b / d b$ - ex mice had a frequency of $5.8 \pm 0.5(\mathrm{n}=8, \mathrm{P}<$ $0.001)$. The voiding frequency of diabetic $(d b / d b)$ sedentary and exercised mice is shown in the Figure 2-3 and the pattern of voiding frequency in the $d b / d b$ sedentary and $d b / d b$ - ex is shown in the Figure 2-4.

The voiding frequency in sedentary WT mice was $3.8 \pm 0.5$ and in the WT- ex group was $2.8 \pm$ 0.4). Voiding frequency was measured over an overnight 12 hour period. The voiding frequency in the WT sedentary and exercised groups is shown in the Figure 2-3 and the pattern of voiding frequency is shown in the Figure 2-4.

\subsubsection{Cystometry}

Representative traces from the cystometrograms of WT and $d b / d b$ mice (sedentary and exercised) are shown in the Figures 2-5a-d, Figure 2-6 and the urodynamic parameters are listed in table 2-2. 


\subsubsection{Pharmacology of bladder strips}

Contractility of mouse bladder strips to $\mathrm{KCl}(8 \mathrm{mM}-127 \mathrm{mM})$ is shown in the Figure 2-7c and 2-

7d. Carbachol induced contractions $\left(10^{-9}\right.$ to $\left.10^{-4} \mathrm{M}\right)$ were also recorded in exercised and sedentary $d b / d b$ and WT mice (Figure 2-7a and 2-7b). Both sensitivity $\left(\mathrm{EC}_{50}\right)$ and maximum contraction for $d b / d b$ and wt (sedentary and exercised) are summarized in the table 2-3.

\subsection{Discussion}

The urinary bladder is a part of the lower urinary tract (LUT) and has two main functions: storage of urine (bladder filling) and voiding of urine (micturition). Bladder storage problems may manifest as increased urinary frequency, urgency and urinary incontinence. Bladder voiding dysfunction leads to poor emptying, slow flow and increased post void residual urine (Daneshgari et al, 2006). Urinary bladder dysfunction is a common malady that is accompanied by an increased residual urine and bladder volume (Buck, 1974).

In our study, exercise did not affect the body weights of either $d b / d b$ or wild type mice. Body weights were significantly higher in diabetic mice and continued to increase during the exercise regimen. We also assessed the effect of exercise on the blood glucose levels in both $d b / d b$ and WT mice. Blood glucose levels were significantly higher in diabetic mice compared to WT mice and continued to increase over the course of study. In our study, 8 weeks of exercise regimen did not decrease or alter the blood glucose levels of either $d b / d b$ or WT mice.

We examined urinary incontinence in female diabetic mice and showed that moderate exercise significantly reduced voiding frequency. Sedentary $d b / d b$ mice had higher 12- hour voiding frequencies than $d b / d b$ ex- mice. Exercise had a significant effect on the voiding frequency of $d b / d b$ mice but it did not alter the micturition frequency of WT mice. We further assessed the voiding pattern and observed that WT mice showed a characteristic pattern of 
voiding at the margins of the cage whereas diabetic mice had a more random distribution of urination over the filter paper, indicative of frequent voiding.

As a next step we examined urodynamic parameters of intact diabetic mice to confirm the findings of voiding pattern test. The cystometry data confirmed bladder dysfunction and incontinence in $d b / d b$ mice as measured by increased voiding frequency, bladder capacity, residual volume and micturition pressure; these data are consistent with previous findings in mice models of type 1 diabetes ${ }^{16}$. An increased bladder capacity with increased residual volumes and high micturition pressures indicates end stage bladder failure in diabetic $(\mathrm{db} / \mathrm{db})$ sedentary mice. Exercise significantly reduced these indicators of urodynamic function in the diabetic mice and did not alter urodynamic function in control (WT sedentary or exercise) mice.

We performed tissue pharmacology studies to investigate if exercise directly affected the contractility of bladder smooth muscle. We studied the response to muscarinic stimulation with carbachol in isolated bladder strips. Parasympathetic regulation of bladder smooth muscle function is altered during diabetes (Latifpour et al, 1988; Longhurst and Belis, 1986). KCl (nonreceptor mediated activation) and carbachol (receptor mediated activation) are commonly used for bladder contractility studies. Increased contractility and sensitivity of bladder strips to $\mathrm{KCl}$ was measured in tissues from sedentary diabetic mice compared to WT sedentary mice. Exercise did not alter the contractility or sensitivity of isolated bladder strips in mice. There were also no significant differences in carbachol induced contractility in $\mathrm{db} / \mathrm{db}$ sedentary and exercised groups. Both sensitivity $\left(\mathrm{EC}_{50}\right)$ and maximum contraction to carbachol were greater in the diabetic $(d b / d b)$ mice compared to WT mice.

Our results are in concordance with prior studies reporting increased contractility of bladder strips in ob/ob mice to carbachol and of increased responsiveness to carbachol and $\mathrm{KCl}$ in rats with type 1 diabetes (Nobe et al, 2008; Nsabimana and Ojewole, 2008; Tammela et al, 2003). In contrast, there are also reports of decreased or unaltered smooth muscle contractility 
during diabetes (Longhurst and Belis, 1986; Changolkar et al, 2005). The mechanisms underlying the increased bladder contractility we observed is unknown, although it has been reported that diabetes results in up-regulation of the bladder muscarinic receptors (Latifpour et al, 1988).

In this study, diabetic mice demonstrated overactivity of bladder, which was improved by exercise. Although exercise did not alter the contractility of isolated bladder tissue, a mechanism of exercise- induced changes in bladder function could be attributed to an increased blood flow to the bladder. Urinary retention during bladder dysfunction is associated with decreased blood flow to bladder muscle (Saito and Miyagawa, 2001). It is possible that exercise increases blood flow to urinary bladder and thus improves bladder function. Other studies in diabetic mice using a similar exercise protocol demonstrated that exercise likely improves blood flow by increasing antioxidant defenses and augmenting nitric oxide bioavailability (Moien-Afshari et al, 2008). Exercise training increases vascular shear stress leading to up- regulation of free-radical scavengers and nitric oxide synthase (Hambrecht et al, 2000). Additional studies are needed to confirm that exercise improves blood flow to the bladder of diabetic mice.

Bladder function of storage and voiding requires proper coordination between bladder detrusor and sphincter muscles, a mechanism of contraction and relaxation activity. Voiding requires sphincter muscles to relax for proper evacuation. There are alterations in urethral sphincter activity during diabetes leading to retention and increase in post void residual urine (Liu et al, 2008). It is also possible that exercise improves the sphincter muscle function by restoring the urethral relaxation and thus improving voiding function in $d b / d b$ mice.

Exercise has beneficial effects on many organ systems. The effects of exercise training on the cardiovascular system are well known (Leung et al, 2008; Kokkinos P, 2008; Leung et al, 2009). As far as we are aware, there are no other studies done that have assessed the effects of exercise on bladder function in diabetes. We demonstrate for the first time that exercise improves 
bladder function in diabetic mice by reducing voiding frequency but further studies are required to assess the mechanisms underlying this effect.

\section{Conclusion}

Diabetic $(\mathrm{d} b / \mathrm{db})$ mice demonstrated an increased voiding frequency, alterations in voiding patterns, increased bladder overactivity, increases in bladder capacity, increased post void residual volume and micturition pressure compared to $d b / d b$ ex and WT groups. Exercise decreased the voiding frequency and improved urodynamic parameters in $d b / d b$ mice. Exercise did appreciably not alter detrusor contractility in $d b / d b$ mice. Our findings suggest that exercise can be considered as a potential preventive strategy in overcoming bladder dysfunction and incontinence in diabetes. The results of our data are an intriguing starting point for further investigations to elucidate the mechanisms of exercise related improvements in bladder function in mice. 


\begin{tabular}{|l|l|l|l|l|l|l|l|l|l|l|l|l|l|l|}
\hline Day & 1 & 2 & 3 & 4 & 5 & 8 & 9 & 10 & 11 & 12 & 13 & 14 & 15 & $\ldots . .$. \\
\hline Exercise & 2.5 & 2.6 & 2.8 & 3.0 & 3.2 & 3.4 & 3.6 & 3.9 & 4.2 & 4.6 & 5.2 & 5.2 & 5.2 & Continues \\
Speed \\
(meters/ \\
min)
\end{tabular}

Table 2-1: Exercise training protocol for mice 


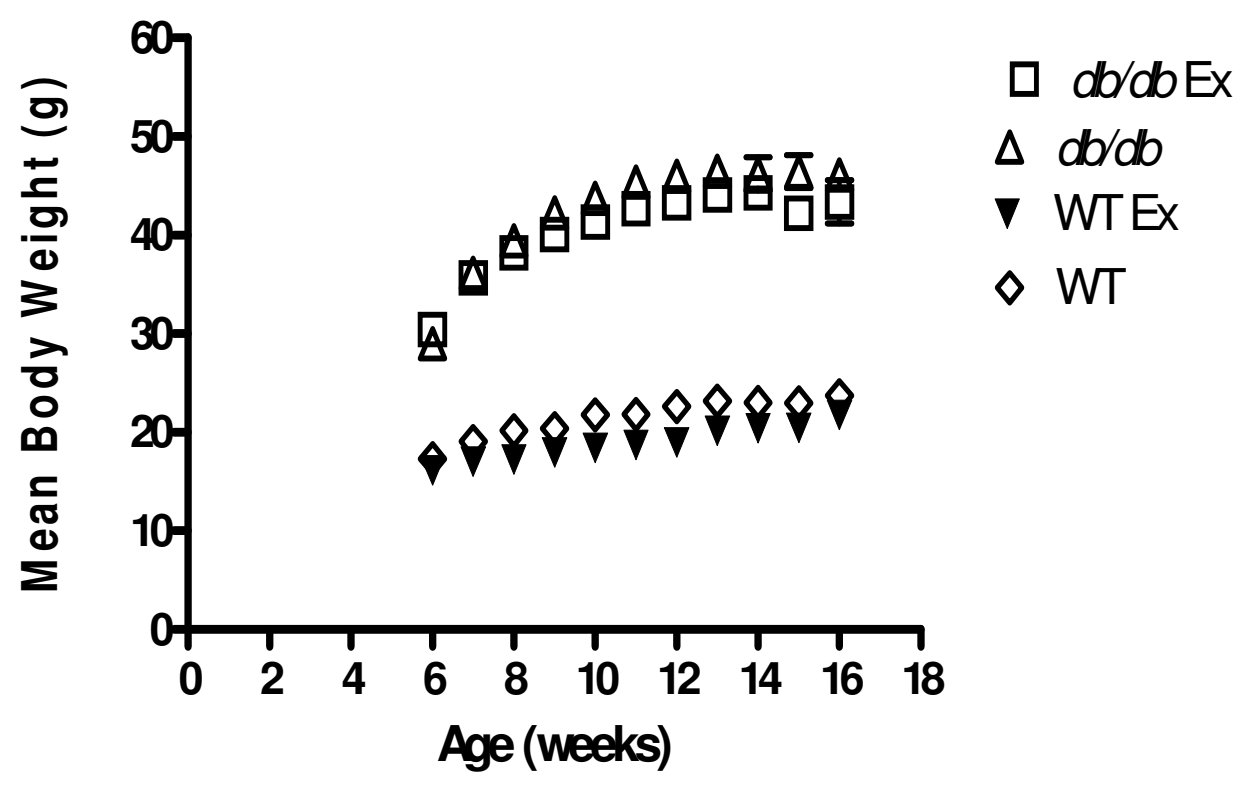

Figure 2-1: Age and exercise related changes in the body weights measured on weekly basis for $d b / d b$ sedentary (not exercised), $d b / d b$ ex (exercised), WT sedentary and WT ex groups. There was a significant difference between the diabetic sedentary and WT groups at all time points $(\mathrm{n}=$ 8 per group, $\mathrm{p}<0.01$, repeated measures ANOVA for $d b / d b$ vs. WT). ex; exercise, WT; wild type. Results are expressed as Mean \pm SEM. 


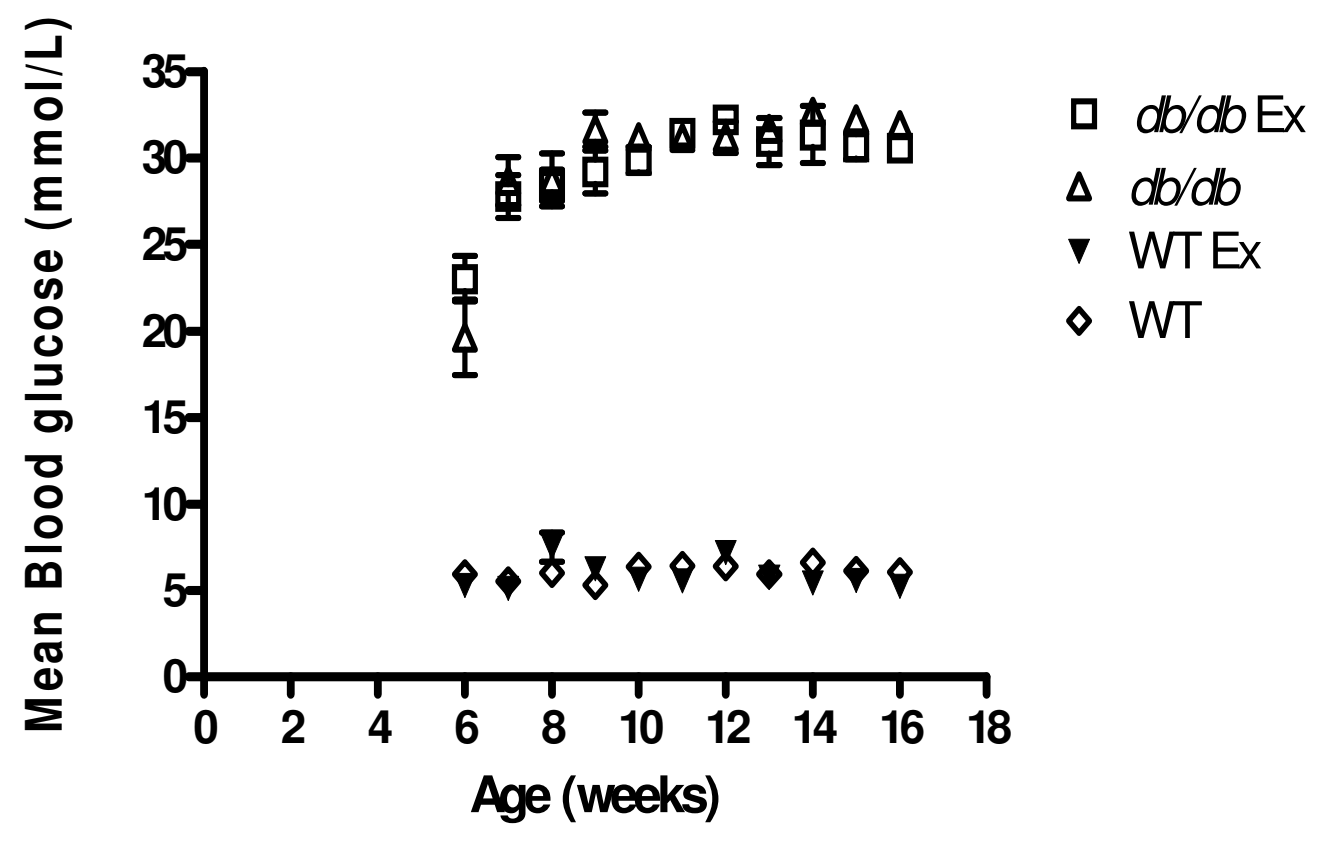

Figure 2-2: Age and exercise related changes in the blood glucose levels measured weekly for $d b / d b$ sedentary, $d b / d b$ ex, WT sedentary and WT ex. There was a significant difference between the diabetic sedentary and WT groups at all time points $(\mathrm{n}=8$ per group, $\mathrm{p}<0.01$, repeated measures ANOVA, for $d b / d b$ vs. WT). ex; exercise, WT; wild type. Results are expressed as Mean \pm SEM 


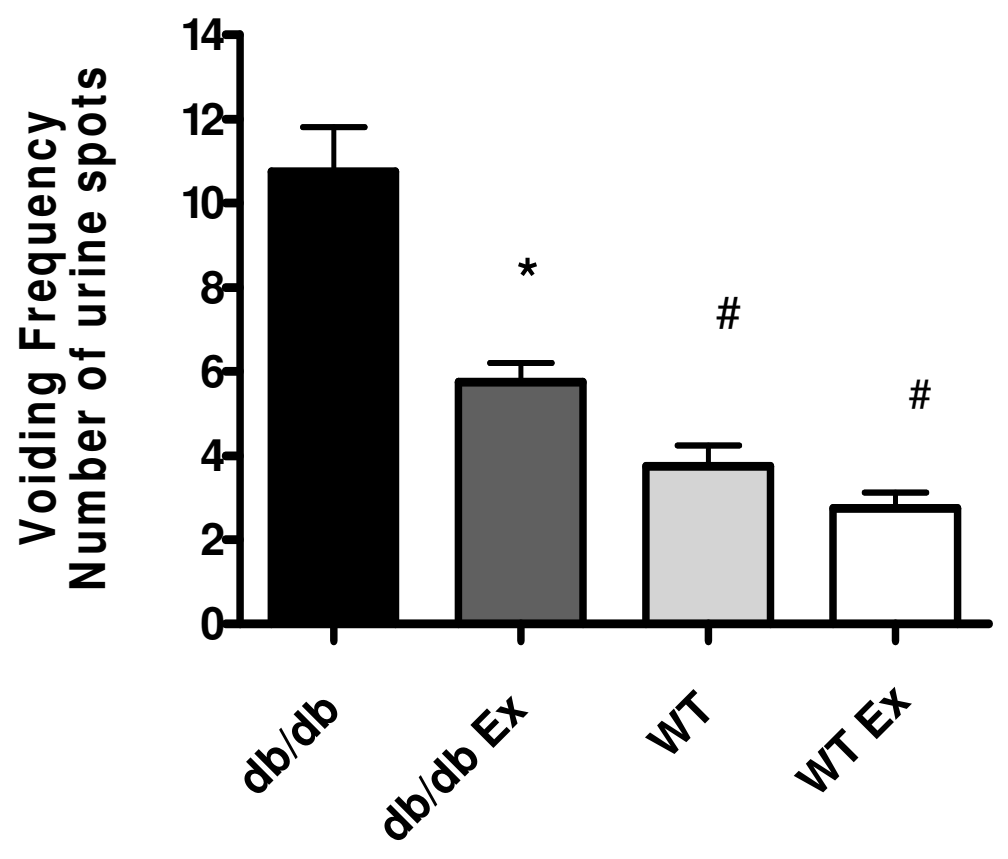

Figure 2-3: Voiding frequency (number of urine spots) for $d b / d b$ sedentary and $d b / d b$ ex, WT sedentary and WT ex groups. There was a significant decrease in the frequency of voiding in $d b / d b$ ex (exercised) group. ( $\mathrm{n}=8,{ }^{*} \mathrm{p}<0.001, d b / d b$ ex vs. $d b / d b$ sedentary; ${ }^{\#} \mathrm{P}<0.001$, WT and WT ex vs. $d b / d b$ sedentary, one- way ANOVA). ex; exercise, WT; wild type. Results are Mean \pm SEM. 


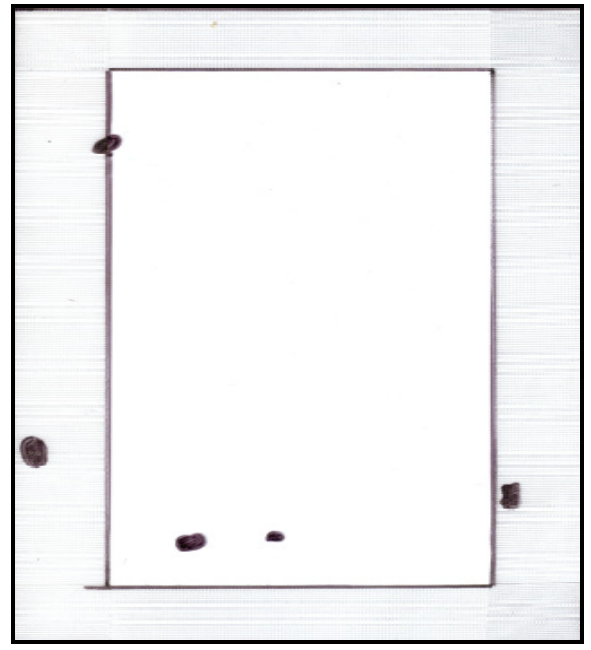

Figure 2-4 a: WT sedentary voiding pattern

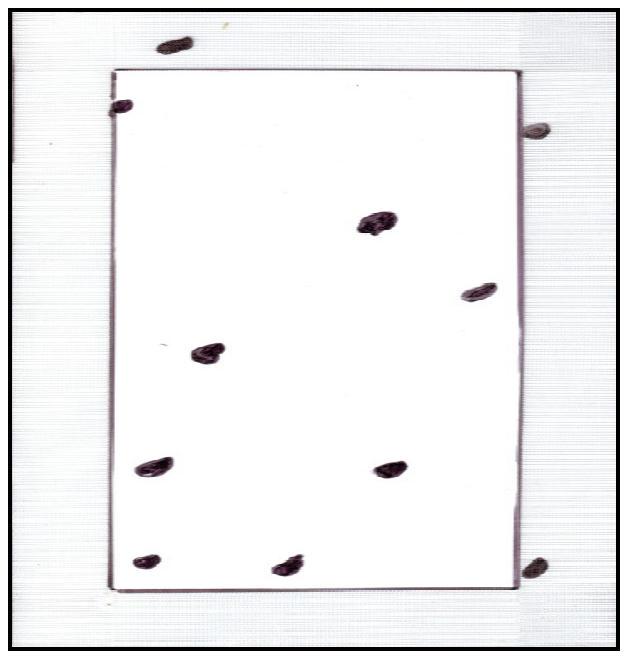

Figure 2-4 c: $d b / d b$ sedentary voiding pattern

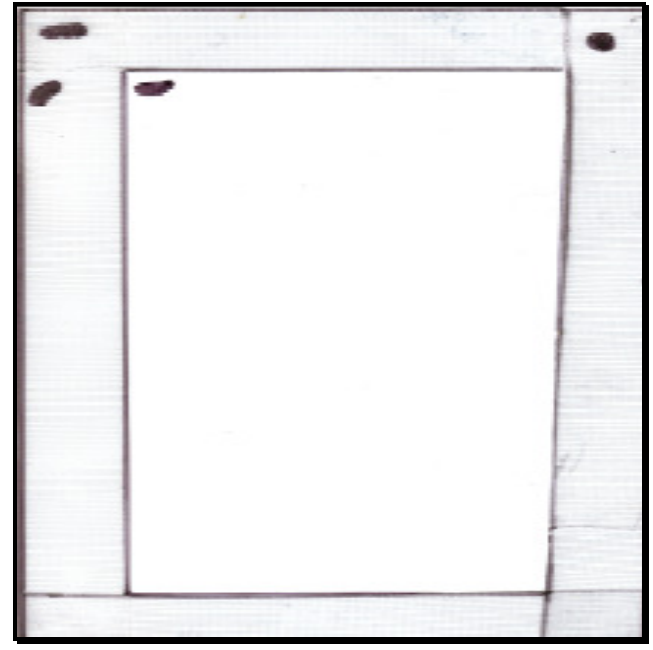

Figure 2-4 b: WT ex voiding pattern

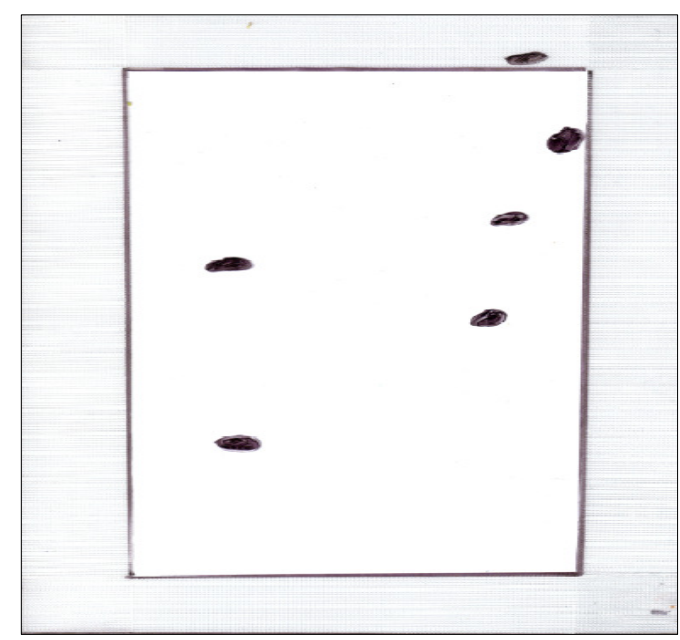

Figure 2-4 d: $d b / d b$ ex voiding pattern

Figure 2-4: Voiding pattern recording of both $d b / d b$ and WT (sedentary and exercised) mice.

Shaded area along the outer edge denotes the periphery of the cage. Urine spots are represented by darkened markings in the figure. WT mice show voiding at the margins of the cage whereas $d b / d b$ mice have a random distribution of voiding. ex; exercise, WT; wild type 
Table 2-2: Urodynamic parameters obtained after performing cystometry on diabetic $(\mathrm{d} b / \mathrm{db})$ and WT, both sedentary and exercised mice. Bcap, bladder capacity, ml; MV, micturition volume, ml; PVR, post void residual volume, $\mathrm{ml}$; $\mathrm{BP}$, basal pressure, $\mathrm{cmH}_{2} \mathrm{O}$; $\mathrm{TP}$, threshold pressure, $\mathrm{cmH}_{2} \mathrm{O}$; MP, micturition pressure, $\mathrm{cmH}_{2} \mathrm{O}$; IMP, intermicturition pressure, $\mathrm{cmH}_{2} \mathrm{O}$; $\mathrm{SA}$, spontaneous activity, IMP-BP; Bcom, bladder compliance $\mathrm{ml} / \mathrm{cmH}_{2} \mathrm{O} ; \mathrm{MF}$, micturition frequency. Data are expressed as Mean \pm SEM. Statistical analysis of differences was performed using one- way ANOVA; values of $\mathrm{P}<0.05$ are taken as statistically significant. a significantly different from $d b / d b$ sedentary group. 


\begin{tabular}{|c|c|c|c|c|c|c|c|c|c|c|}
\hline $\begin{array}{l}\text { Animal } \\
\text { Group }\end{array}$ & $\begin{array}{l}\text { Bladder } \\
\text { capacity } \\
\text { (Bcap, } \\
\text { ml) }\end{array}$ & $\begin{array}{l}\text { Micturition } \\
\text { Volume } \\
\text { ( MV, ml) }\end{array}$ & $\begin{array}{l}\text { Post } \\
\text { void } \\
\text { residual } \\
\text { (PVR, } \\
\text { ml) }\end{array}$ & $\begin{array}{l}\text { Basal } \\
\text { Pressure } \\
(\mathrm{BP}, \\
\left.\text { cmH }_{2} \mathrm{O}\right)\end{array}$ & $\begin{array}{l}\text { Threshold } \\
\text { Pressure } \\
(\mathrm{TP}, \\
\left.\mathrm{cmH}_{2} \mathrm{O}\right)\end{array}$ & $\begin{array}{l}\text { Micturition } \\
\text { Pressure } \\
(\mathrm{MP}, \\
\left.\mathrm{cmH}_{2} \mathrm{O}\right)\end{array}$ & $\begin{array}{l}\text { Inter } \\
\text { Micturition } \\
\text { Pressure } \\
(\text { IMP, } \\
\left.\text { cmH }{ }_{2} \mathrm{O}\right)\end{array}$ & $\begin{array}{l}\text { Spontaneous } \\
\text { Activity } \\
\text { (SA) }\end{array}$ & $\begin{array}{l}\text { Bladder } \\
\text { compliance } \\
\left(\mathbf{m l} / \mathrm{cmH}_{2} \mathrm{O}\right)\end{array}$ & $\begin{array}{l}\text { Micturition } \\
\text { Frequency } \\
\text { (MF, per } \\
\text { hour) }\end{array}$ \\
\hline$d b / d b$ & $\begin{array}{l}0.28 \pm \\
0.07\end{array}$ & $0.13 \pm 0.02$ & $\begin{array}{l}0.2 \pm \\
0.03\end{array}$ & $\begin{array}{l}16.27 \pm \\
1.8\end{array}$ & $\begin{array}{l}23.91 \pm \\
2.03\end{array}$ & $30.6 \pm 1.7$ & $18.0 \pm 2.25$ & $1.7 \pm 0.54$ & $0.03 \pm 0.01$ & $13 \pm 0.82$ \\
\hline $\begin{array}{l}d b / d b \\
\mathrm{Ex}\end{array}$ & $\begin{array}{l}0.14 \pm \\
0.02^{\mathrm{a}}\end{array}$ & $0.1 \pm 0.05$ & $\begin{array}{l}0.06 \pm \\
0.02^{\mathrm{a}}\end{array}$ & $\begin{array}{l}13.73 \pm \\
2.0\end{array}$ & $\begin{array}{l}18.78 \pm \\
1.6\end{array}$ & $25.9 \pm 1.7^{\mathrm{a}}$ & $\begin{array}{l}15.31 \pm \\
2.05\end{array}$ & $1.58 \pm 0.32$ & $0.04 \pm 0.01$ & $10.43 \pm 0.1$ \\
\hline WT & $\begin{array}{l}0.1 \pm \\
0.02^{\mathrm{a}}\end{array}$ & $0.06 \pm 0.01$ & $\begin{array}{l}0.04 \pm \\
0.03^{\mathrm{a}}\end{array}$ & $\begin{array}{l}14.1 \pm \\
0.5\end{array}$ & $\begin{array}{l}25.06 \pm \\
2.1\end{array}$ & $32.6 \pm 2.3^{\mathrm{a}}$ & $15.4 \pm 0.54$ & $0.42 \pm 0.12$ & $0.02 \pm 0.01$ & $11.9 \pm 1.12$ \\
\hline WT Ex & $\begin{array}{l}0.1 \pm \\
0.01^{\mathrm{a}}\end{array}$ & $0.08 \pm 0.01$ & $\begin{array}{l}0.01 \pm \\
0.01^{\mathrm{a}}\end{array}$ & $\begin{array}{l}17.03 \pm \\
1.8\end{array}$ & $\begin{array}{l}24.75 \pm \\
1.3\end{array}$ & $32.6 \pm 0.1^{\mathrm{a}}$ & $17.7 \pm 2.07$ & $0.69 \pm 0.3$ & $0.02 \pm 0.01$ & $11.2 \pm 0.9$ \\
\hline
\end{tabular}



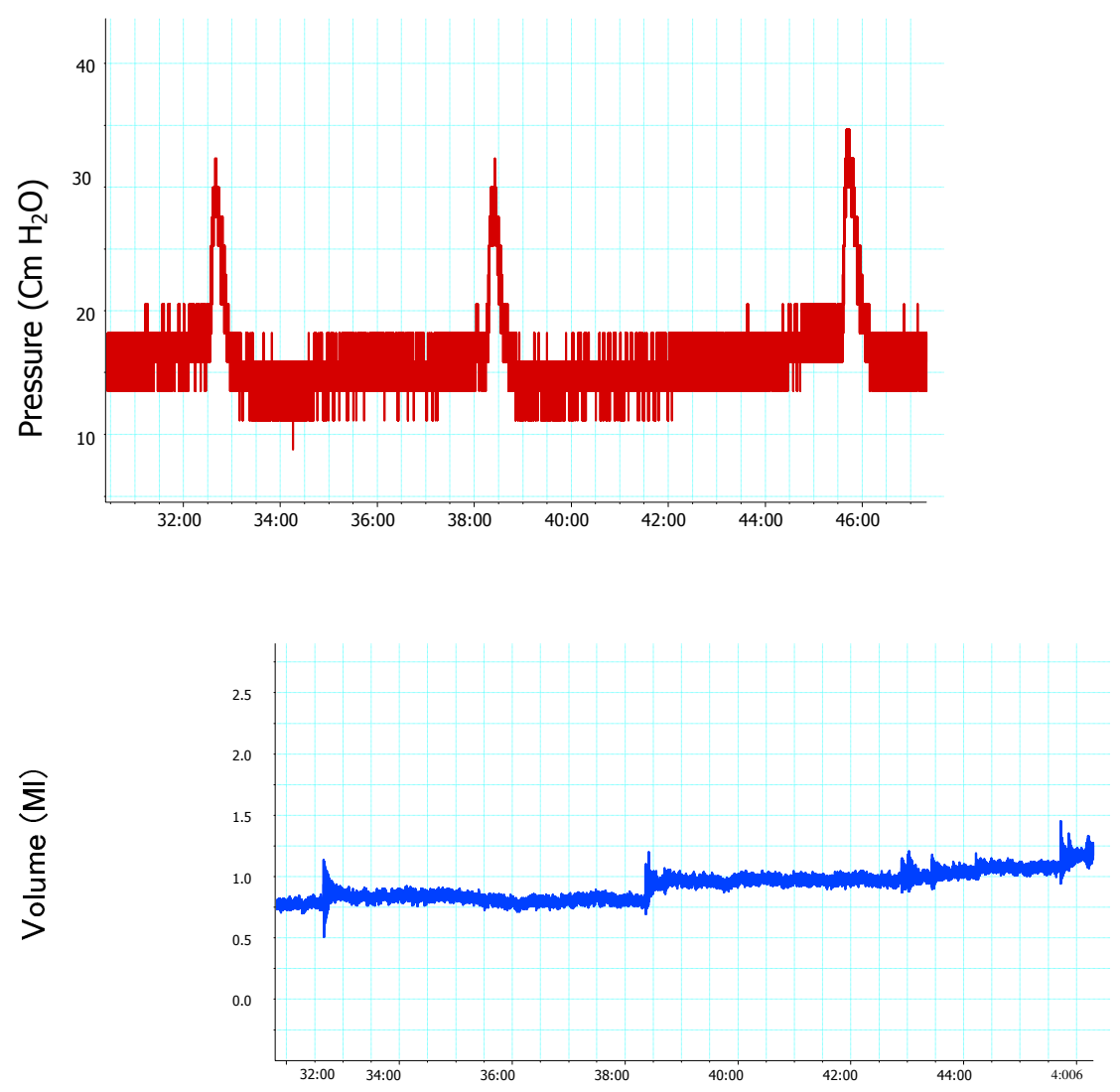

Figure 2-5a: Representative cystometrogram tracing of the diabetic $(d b / d b)$ mice. Micturition pressure (red tracing) with $\mathrm{X}$-axis indicating pressure $\left(\mathrm{cmH}_{2} \mathrm{O}\right)$ and $\mathrm{Y}$ - axis indicating time (minutes: seconds). Micturition volume (blue tracing) with $\mathrm{X}$-axis indicating volume $(\mathrm{ml})$ and $\mathrm{Y}$ - axis indicating time (minutes: seconds). Voiding efficiency is reduced and micturition pressure is high indicating bladder dysfunction in $d b / d b$ sedentary mice. Spontaneous activity is increased indicating overactive bladder which is a clinical correlate of urgency. 

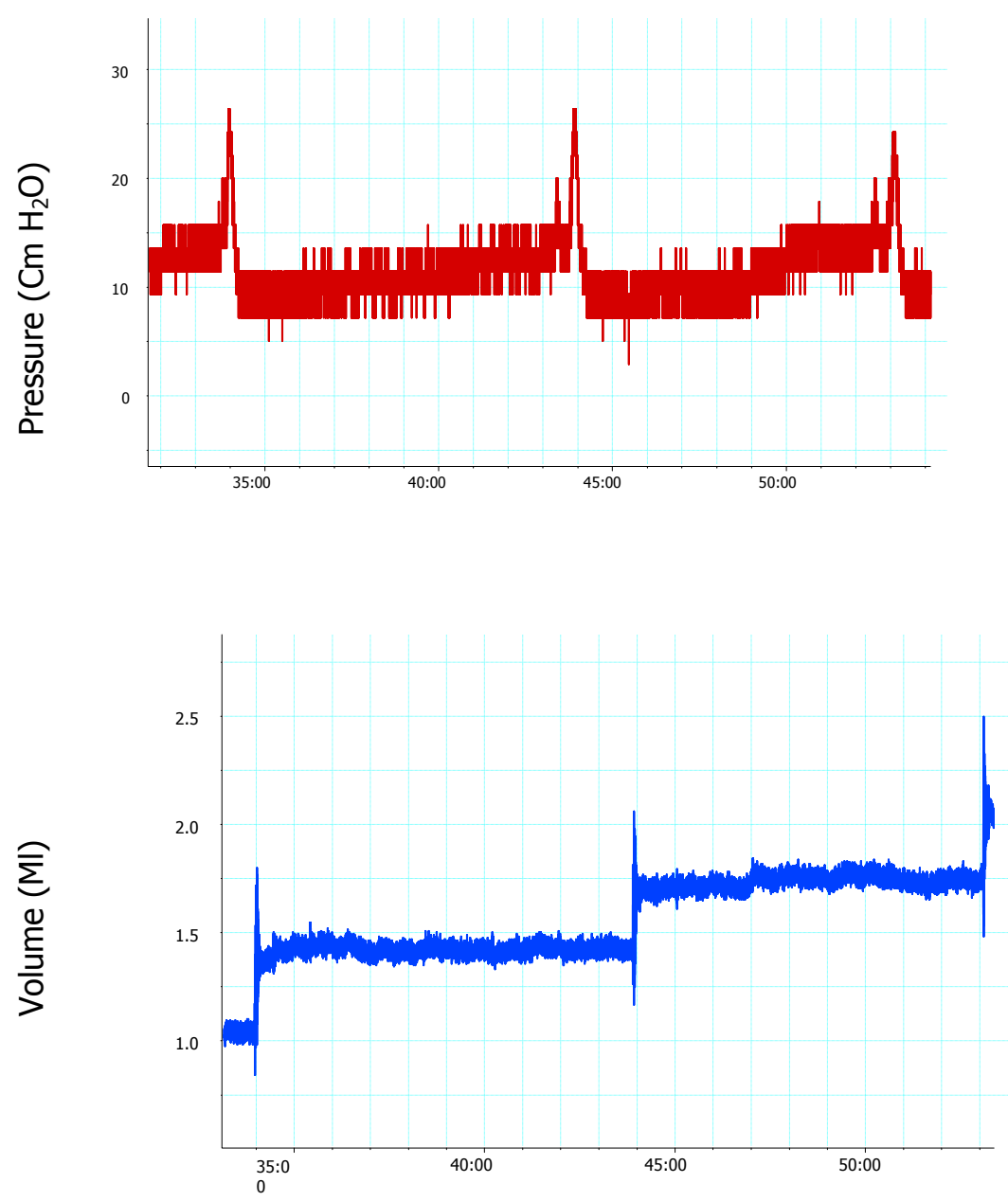

Figure 2-5b: Representative cystometrogram tracing from the diabetic $(d b / d b)$ ex mice. Micturition pressure (red tracing) with $\mathrm{X}$-axis indicating pressure $\left(\mathrm{cmH}_{2} \mathrm{O}\right)$ and $\mathrm{Y}$ - axis indicating time (minutes: seconds). Micturition volume (blue tracing) with $\mathrm{X}$-axis indicating volume (ml) and $\mathrm{Y}$ - axis indicating time (minutes: seconds). Regular micturition patterns and low micturition pressure in $d b / d b$ ex mice indicates efficient voiding. ex; exercise. 

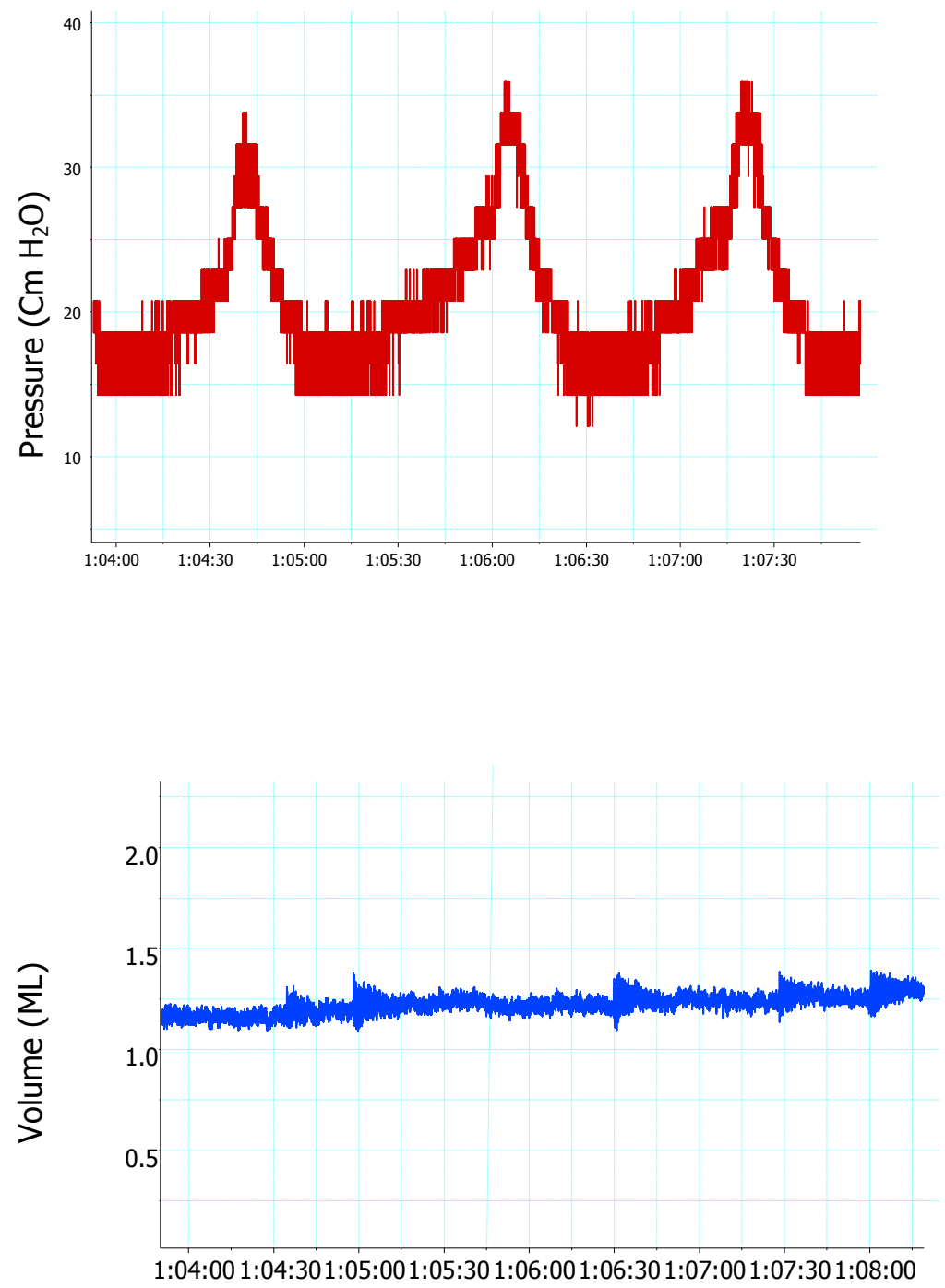

Figure 2-5c: Representative cystometrogram tracing from the wild type (WT) mice. Micturition pressure (red tracing) with $\mathrm{X}$-axis indicating pressure $\left(\mathrm{cmH}_{2} \mathrm{O}\right)$ and $\mathrm{Y}$ - axis indicating time (hours: minutes: seconds). Micturition volume (blue tracing) with X-axis indicating volume (ml) and Y- axis indicating time (hours: minutes: seconds). WT; wild type. 

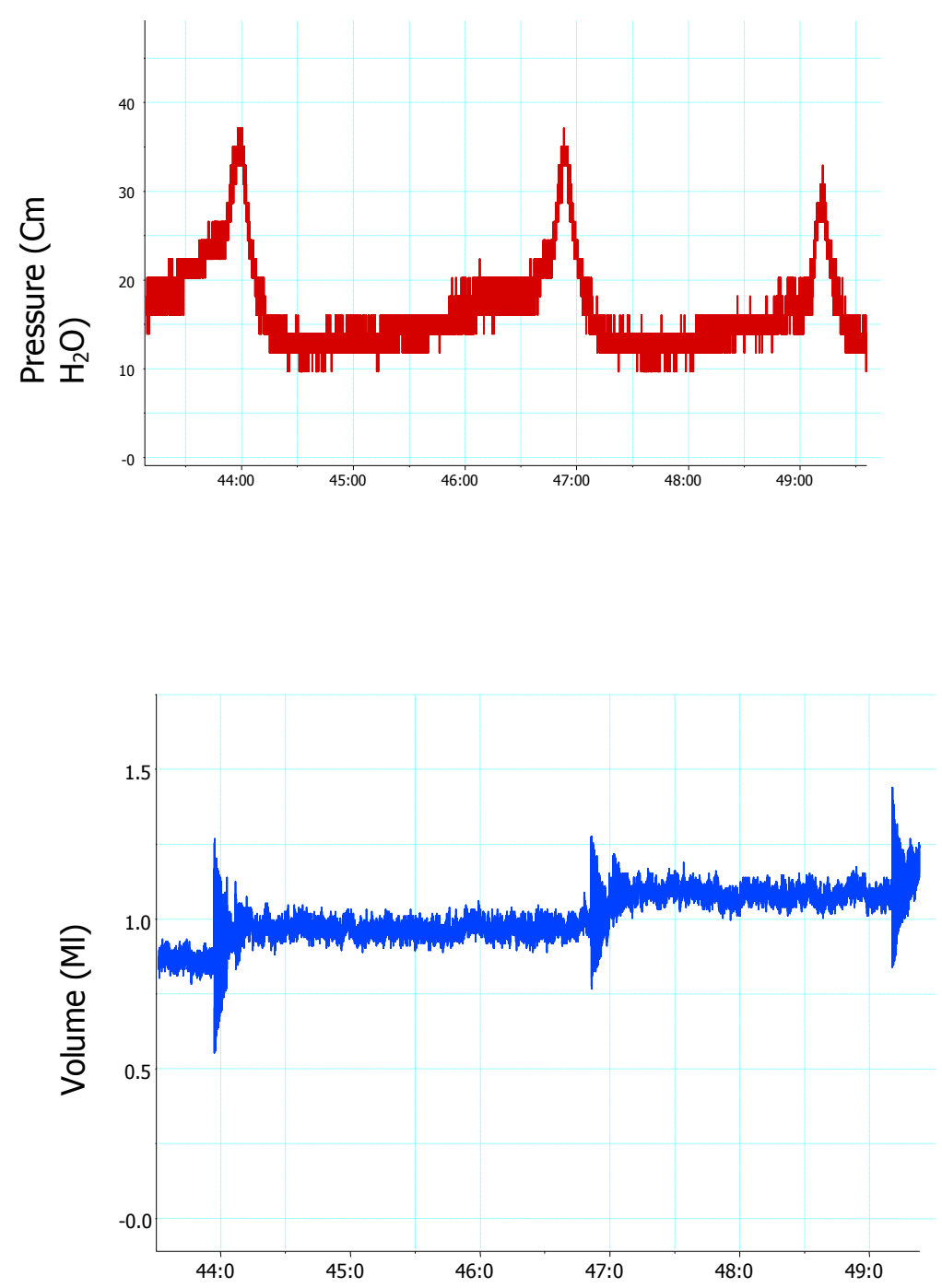

Figure 2- 5d: Representative cystometrogram tracing from the wild type (WT) ex mice. Micturition pressure (red tracing) with $\mathrm{X}$-axis indicating pressure $\left(\mathrm{cmH}_{2} \mathrm{O}\right)$ and $\mathrm{Y}$ - axis indicating time (minutes: seconds). Micturition volume (blue tracing) with X-axis indicating volume $(\mathrm{ml})$ and $\mathrm{Y}$ - axis indicating time (minutes: seconds). ex; exercise, WT; wild type. 


$$
\text { 2-6 a. }
$$
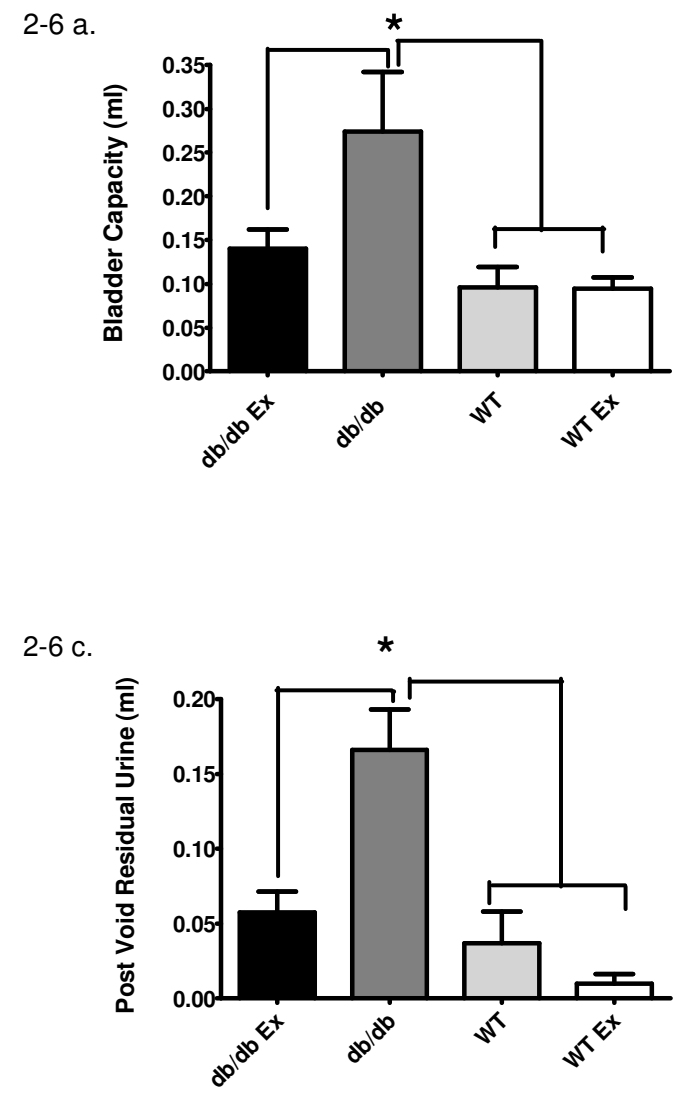

2-6 b.

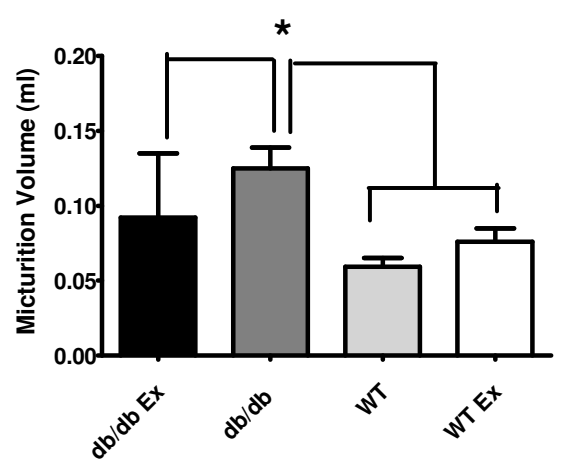

$2-6 d$.

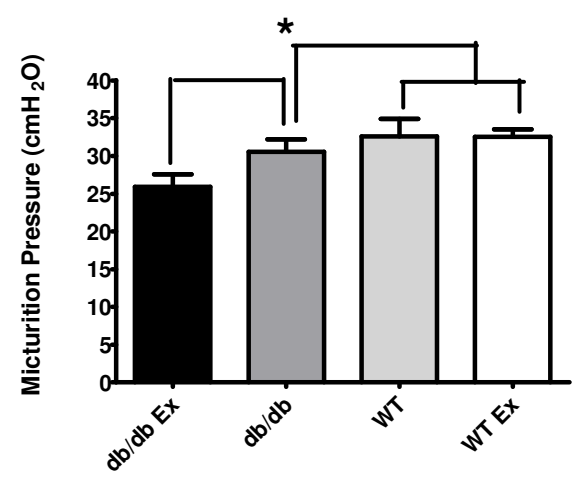

Figure 2- 6: Bladder capacity, micturition volume, residual urine volume and micturition pressure were greatly elevated in $d b / d b$ sedentary mice compared to WT (sedentary and exercised) mice. Exercise reduced these urodynamic parameters significantly in $d b / d b$ ex mice. Voiding efficiency is increased in $d b / d b$ ex mice indicating complete evacuation with minimal retention of urine. $(\mathrm{n}=4-6, * \mathrm{P}<0.05$, ANOVA). Results are Mean \pm SEM. ex, exercise; WT, wild type. 


\begin{tabular}{|l|l|l|l|}
\hline Animal Group & n & \multicolumn{2}{|c|}{ Carbachol } \\
\cline { 3 - 4 } & & Log $\mathbf{E C}_{\mathbf{5 0}}(\mathbf{m o l} / \mathbf{l})$ & $\begin{array}{l}\mathbf{E}_{\max }(\% \text { maximum } \\
\text { contraction })\end{array}$ \\
\hline$d b / d b$ & & & $109.3 \pm 10.19$ \\
\hline$d b / d b$ Ex & 4 & $-6.61 \pm 0.11$ & $91.13 \pm 8.76$ \\
\hline WT & 6 & $-6.68 \pm 0.25$ & $103.99 \pm 16.63$ \\
\hline WT Ex & 5 & $-6.01 \pm 0.068$ & $105.44 \pm 17.46$ \\
\hline
\end{tabular}

Table 2-3: $\mathrm{EC}_{50}$ and maximum contraction response for carbachol induced concentration dependent contractions of $d b / d b$ (not exercised), $d b / d b$ ex (exercised), WT (not exercised) and WT ex (exercised); $\mathrm{EC}_{50}$ and $\mathrm{E}_{\max }$ values were not significant amongst the groups. ex; exercise, WT; wild type. Values are Mean \pm SEM. 

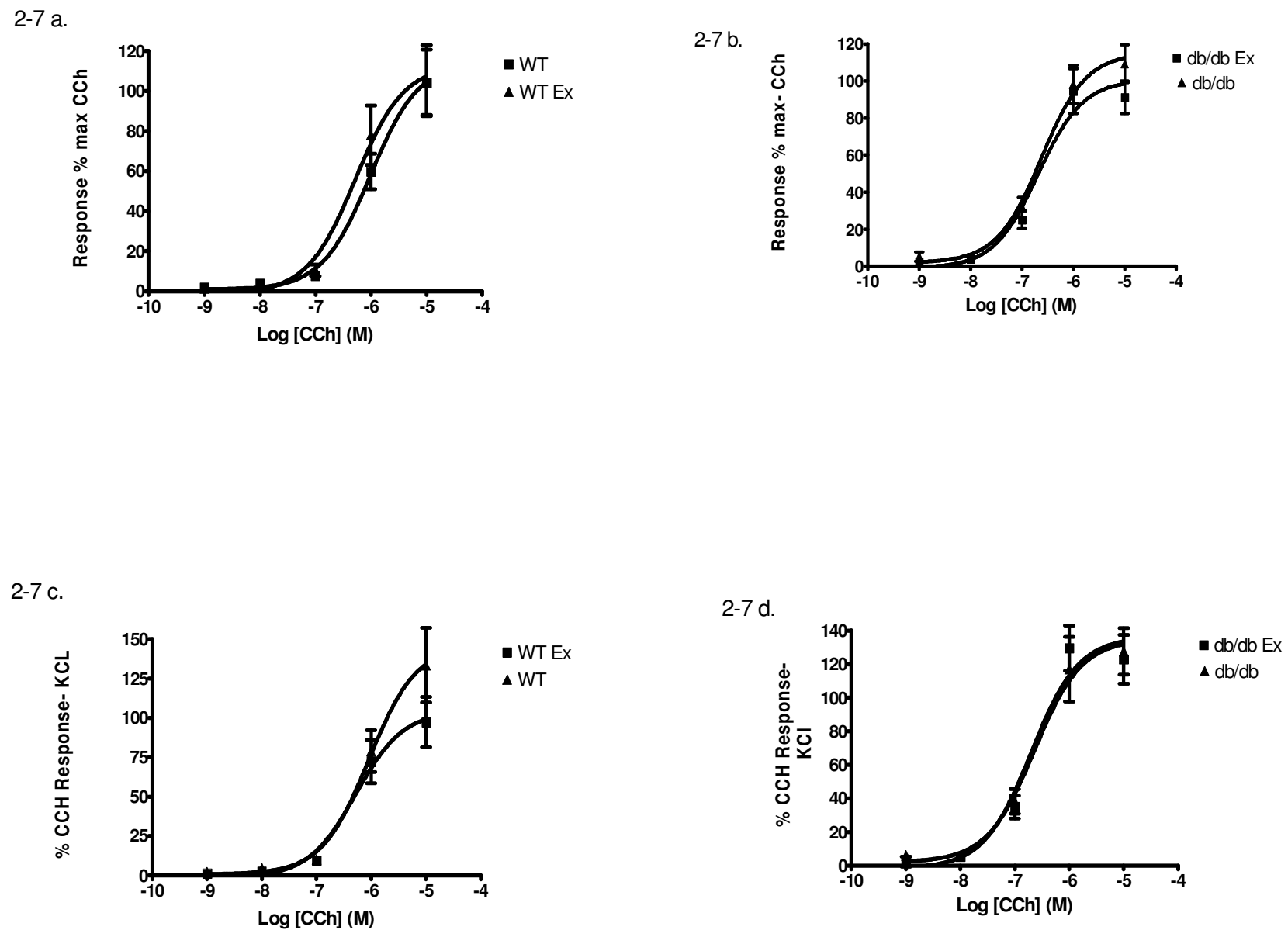

Figure 2-7: Carbachol induced contraction and percent maximum response to KCL between $d b / d b$ sedentary (not exercised), $d b / d b$ ex (exercised), WT sedentary (not exercised) and WT ex (exercised). The maximum contractile responses were not significant amongst the groups. $(n=4-6$ per group, repeated measures ANOVA, P > 0.05) ex; exercise, WT; wild type. Values are expressed as Mean \pm SEM. 


\subsection{Bibliography}

Abrams P, Cardozo L, Fall M, Griffiths D, Rosier P, Ulmsten U, Van Kerrebroeck P, Victor A, Wein A; Standardisation Sub-Committee of the International Continence Society (2003) The standardisation of terminology in lower urinary tract function: report from the standardisation sub-committee of the International Continence Society. Urology, 61(1): 37- 49 .

Aboushwareb T, Zhou G, Deng FM, Turner C, Andersson KE, Tar M, Zhao W, Melman A, D'Agostino R Jr, Sun TT, Christ GJ (2009) Alterations in bladder function associated with urothelial defects in uroplakin II and IIIa knockout mice, Neurourol Urodyn. [Epub ahead of print].

Brown JS, Wessells H, Chancellor MB, Howards SS, Stamm WE, Stapleton AE, Steers WD, Van Den Eeden SK, McVary KT (2005) Urologic complications of diabetes, Diabetes Care, 28 (1): 177- 185.

A C Buck, The Diabetic Bladder (1974) Proc. roy. Soc. Med, Volume 67.

Canadian continence foundation (2006) Ref Type: Electronic citation. http://www.continence-fdn.ca/ 
Changolkar AK, Hypolite JA, Disanto M, Oates PJ, Wein AJ, Chacko S (2005) Diabetes induced decrease in detrusor smooth muscle force is associated with oxidative stress and overactivity of aldose reductase . J Urol, 173 (1): 309- 313.

Cornelissen LL, Misajet B, Brooks DP, Hicks A (2008) Influence of genetic background and gender on bladder function in the mouse Auton Neurosci, 140 (1-2): 53- 58.

Danforth KN, Townsend MK, Curhan GC, Resnick NM, Grodstein F. (2009) Type 2 diabetes mellitus and risk of stress, urge and mixed urinary incontinence. J Urol, 181 (1): 193- 197.

Daneshgari F, Huang X, Liu G, Bena J, Saffore L, Powell CT (2006) Temporal differences in bladder dysfunction caused by diabetes, diuresis, and treated diabetes in mice. Am J Physiol Regul Integr Comp Physiol, 290(6): R1728- 1735.

Duncan GE, Exercise, fitness, and cardiovascular disease risk in type 2 diabetes and the metabolic syndrome (2006) Curr Diab Rep, 6 (1): 29- 35.

Kebapci N, Yenilmez A, Efe B, Entok E, Demirustu C (2007) Bladder dysfunction in type 2 diabetic patients. Neurourol Urodyn, 26 (6): 814- 819. 
Kokkinos P (2008) Physical activity and cardiovascular disease prevention: current recommendations, Angiology, 59: 26S-29S.

Latifpour J, Gousse A, Kondo S, Morita T, Weiss RM (1988) Effects of experimental diabetes on biochemical and functional characteristics of bladder muscarinic receptors. $J$ Pharmacol Exp Ther, 248 (1): 81- 88.

Leung FP, Yung LM, Laher I, Yao X, Chen ZY, Huang Y (2008) Exercise, vascular wall and cardiovascular diseases: An update (Part 1) Sports Medicine, 1009- 1024.

Leung FP, Yung LM, Laher I, Yao X, Chen ZY, Huang Y (2009) Exercise, vascular wall and cardiovascular diseases: An update (Part 2) Sports Medicine, 39: 45- 63.

Liang W, Afshar K, Stothers L, Laher I (2002) The influence of ovariectomy and estrogen replacement on voiding patterns and detrusor muscarinic receptor affinity in the rat. Life Sci, 71(3): 351- 362.

Liu G, Lin YH, Yamada Y, Daneshgari F (2008) External urethral sphincter activity in diabetic rats, Neurourol Urodyn, 27 (5): 429- 434.

Longhurst PA, Belis JA (1986) Abnormalities of Rat Bladder Contractility in Streptozotocin- Induced Diabetes Mellitus. J Pharmacol Exp Ther, 238 (3): 773-777. 
McIntosh, C.H., and Pederson, R.A. Non-insulin dependent animal models of diabetes melliltus. CRC Critical Reviews. Experimental Models of Diabetes. Ed. J.H.McNeill, Boca Baton, CRC Press Ltd, Pages 337- 398.

Moien-Afshari F, Ghosh S, Elmi S, Rahman MM, Sallam N, Khazaei M, Kieffer TJ, Brownsey RW, Laher I., (2008) Exercise restores aortic endothelial function independent of weight loss or hyperglycaemic status in db/db mice. Diabetologia, 51(7): 1327-1337.

Nobe K, Yamazaki T, Tsumita N, Hashimoto T, Honda K (2008) Glucose-Dependent Enhancement of Diabetic Bladder Contraction Is Associated with a Rho KinaseRegulated Protein Kinase C Pathway. J Pharmacol Exp Ther, 328 (3): 940- 950.

O'Neil B, Gilmour D. Approach to urinary incontinence in women. Diagnosis and management by family physicians Can Fam Physician, 49: 611- 618.

Nsabimana AM, Ojewole JA (2008) Diabetes mellitus and responses of the urinary bladder to acetylcholine: an in vitro study. J Smooth Muscle Res, 44(3-4): 143- 150.

Saito M, Miyagawa I (2001) Bladder dysfunction after acute urinary retention in rats. $J$ Urol, 165 (5): 1745- 1747.

Srinivasan K, Ramarao P (2007) Animal models in type 2 diabetes research: An overview. Indian J Med Res, 125: 451- 472. 
Tammela TL, Leggett RE, Levin RM, Longhurst PA (2003) Temporal changes in micturition and bladder contractility after sucrose diuresis and streptozotocin-induced diabetes mellitus in rats. $J$ Urol, 153 (6): 2014- 2021.

Wyman J. F., Burgio K. L., Newman D. K. (2009) Practical aspects of lifestyle modifications and behavioural interventions in the treatment of overactive bladder and urgency urinary incontinence. Int J Clin Prac, 63 (8): 177- 191. 


\section{CONCLUSIONS}

\subsection{Conclusions}

Urinary bladder dysfunction is a common complication of diabetes which affects approximately $40-80 \%$ of diabetic patients. It is associated with various symptoms such as urinary incontinence, diabetic cystopathy, urinary tract infection, impaired bladder emptying etc. These symptoms reduce the quality of life and are often irreversible. End stage bladder failure in diabetes results in an increase in bladder capacity, large bladder size, increased post void residual urine and urinary retention. Diabetes also leads to functional impairment of the urinary bladder making it flaccid, hypotonic, and atonic. Urinary incontinence is common in diabetic patients with the frequency being greater in women than in men. There are different forms of incontinence, including stress, urge, overflow and mixed incontinence but urge incontinence is most commonly observed in diabetes.

Though the occurrence of bladder dysfunction in diabetes is well recognized, the underlying mechanisms and pathogenesis remain unknown; this has hampered devising effective management therapies to prevent the symptoms. Exercise is a lifestyle modification used in diabetes as an initial management strategy but its role in regulating bladder dysfunction is unknown. We studied the effect of moderate exercise on urinary bladder dysfunction and incontinence in the $d b / d b$ mouse model of type 2 diabetes.

We observed that exercise did not affect the body weights or blood glucose of either $d b / d b$ or WT mice. Body weights and blood glucose levels were significantly higher in the diabetic mice and continued to increase over the exercise period. Bladder dysfunction and 
incontinence was examined in female $d b / d b$ mice. Exercise significantly reduced the voiding frequency in diabetic mice but it did not alter the voiding frequency in WT mice. The voiding pattern of WT mice displayed characteristics episodes of voiding at the margins of the cage. In contrast, $d b / d b$ mice had a more random distribution of voiding.

Cystometry was performed on animals to record and observe the urodynamic parameters and to confirm the findings obtained from voiding pattern test. Cystometry confirmed incontinence and dysfunction of bladder in diabetic mice based on increases in micturition frequency, bladder capacity, micturition pressure and residual volume. Moderate levels of exercise reduced micturition frequency, bladder capacity, micturition pressure and residual volume and in doing so, led to improved bladder function in diabetic mice.

Response of isolated bladder strips to muscarinic stimulation with carbachol and $\mathrm{KCl}$ were also studied. Diabetic bladder strips showed increased contractility to both carbachol and $\mathrm{KCl}$. In this study, exercise did not alter the contractility or sensitivity of bladder strips in mice suggesting that other mechanisms may be responsible for exercise- induced improvements in bladder function in $d b / d b$ mice.

\subsection{Future studies}

This is the first study to demonstrate that exercise significantly improves urinary bladder function in $d b / d b$ mice. The mechanisms for this effect of exercise are not known but are unlikely to be related to changes in blood glucose or body weight. In devising future studies to further explore the effects of exercise on incontinence during diabetes, the following findings should be considered: 


\section{Increased blood flow to the bladder:}

A study in pigs suggests that increased intravesical pressure principally determines the blood flow to urinary bladder muscle where increased pressure leads to decreased blood flow (Greenland and Brading, 1996). It would be important to explore whether exercise affects blood flow to bladder muscle and then relate this to improved bladder function in diabetes.

The near infrared spectroscopy (NIRS) method has recently been used in urological research for measuring local changes in haemoglobin and oxyhemoglobin (Stothers et al, 2008; Boushel and Piantadosi, 2000). The NIRS method is a non-invasive technique for in vivo monitoring of tissue oxygen availability and utilization and is primarily used to assess tissue oxyhaemoglobin $(\mathrm{tHbO} 2)$, deoxyhaemoglobin $(\mathrm{tHb})$ and the total blood volume (tBV). Since the NIRS method detects changes in muscle oxygenation, it can be used to determine if exercise improves $\mathrm{tHbO} 2, \mathrm{tHb}$ and $\mathrm{tBV}$ in the bladder of diabetic mice.

\section{Oxidative mechanisms in bladder dysfunction:}

Hyperglycemia results in a production of reactive oxygen species (ROS) and leads to increases in oxidative stress in the bladder of type 1 diabetic animals (Beshay and Carrier, 2004). Other studies have demonstrated that exercise increases anti- oxidant defense mechanisms in type 2 diabetes (Moein Afshari et $a l, 2008)$. It will be important to study if exercise improves bladder dysfunction in $d b / d b$ mouse model by reducing oxidative stress and scavenging free radicals such as ROS. 


\section{Menopause and urinary incontinence:}

Post menopausal women experience urogenital problems with urinary incontinence as a major factor (Jackson et al, 2005). It would be important to study the effects of exercise in diabetic menopausal animal models with a focus on incontinence episodes.

\section{Clinical studies:}

Finally, a pilot study to determine if life style modifications such as exercise in type 2 diabetic human subjects provides an additional strategy in the management of urinary incontinence. One proposal would be to document incontinence and NIRS recordings before and after exercise training; this would have an advantage of being a non- surgical and relatively simple intervention. 


\subsection{Bibliography}

Beshay E, Carrier S (2004) Oxidative stress plays a role in diabetes-induced bladder dysfunction in a rat model. Urology, 64 (5): 1062-1067.

Boushel R and Piantadosi C.A (2000) Near infrared spectroscopy for monitoring muscle oxygenation Acta Physiol Scand, 168, 615-622.

Greenland JE, Brading AF (1996) Urinary bladder blood flow changes during the micturition cycle in a conscious pig model. J Urol, 156 (5): 1858-1861.

Jackson S, Scholes D, Boyko EJ, Abraham L, Fihn SD (2005) Urinary Incontinence and Diabetes in Postmenopausal Women. Diabetes Care, 28 (7): 1730-1738.

Moien-Afshari F, Ghosh S, Elmi S, Rahman MM, Sallam N, Khazaei M, Kieffer TJ, Brownsey RW, Laher I., (2008) Exercise restores aortic endothelial function independent of weight loss or hyperglycaemic status in db/db mice. Diabetologia, 51 (7): 1327-1337.

Stothers L, Shadgan B, Macnab A (2008) Urological applications of near infrared spectroscopy. Can J Urol, 15 (6): 4399- 4409. 


\section{APPENDIX}

Page 1 of 1

\section{ANIMAL CARE CERTIFICATE}

Application Number: A06-0277

Investigator or Course Direetor:

Department: Surgery

Animals:

Mice Mice $\mathrm{db} / \mathrm{db} 40$

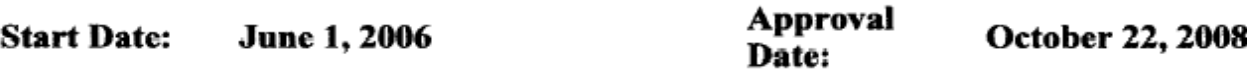

Funding Sources:

Unfunded title: The effects of lifestyle changes, including physical exercise, on bladder function inthe diabetic mouse model

The Animal Care Committee has examined and approved the use of animals for the above experimental project.

This certificate is valid for one year from the above start or approval date (whichever is later) provided there is no change in the experimental procedures. Annual review is required by the CCAC and some granting agencies.

A copy of this certificate must be displayed in your animal facility.

Office of Research Services and Administration

102, 6190 Agronomy Road, Vancouver, BC V6T 1 Z3

Phone: 604-827-5111 Fax: 604-822-5093 